\title{
Signalling through pigment dispersing hormone-like peptides in invertebrates
}

\author{
E. Meelkop ${ }^{1}$, L. Temmerman ${ }^{1}$, L. Schoofs ${ }^{*}$, T. Janssen \\ Laboratory of Functional Genomics and Proteomics, Zoological Institute, K.U. Leuven, Naamsestraat 59, B-3000 Leuven, Belgium
}

\section{A R T I C L E I N F O}

\section{Article history:}

Received 30 April 2010

Received in revised form 19 October 2010

Accepted 21 October 2010

\section{Keywords:}

Pigment dispersing hormone

Pigment dispersing factor

Neuropeptide

Circadian rhythm

\begin{abstract}
A B S T R A C T
During recent decades, several research teams engaged in unraveling the molecular structure and the physiological significance of pigment dispersing hormone-like peptides, particularly with respect to colour change and biological rhythms. In this review, we first summarise the entire history of pigment dispersing hormone-like peptide research, thus providing a steppingstone for those who are curious about this growing area of interest. Next, we try to bring order in the plethora of experimental data on the molecular structure of the various peptides and receptors and also discuss immunolocalisation, timerelated expression and suggested functions in crustaceans, insects and nematodes. In addition, a brief comparison with the vertebrate system is made.
\end{abstract}

(c) 2010 Elsevier Ltd. All rights reserved.

\section{Contents}

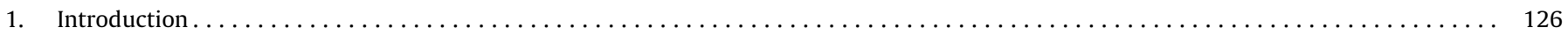

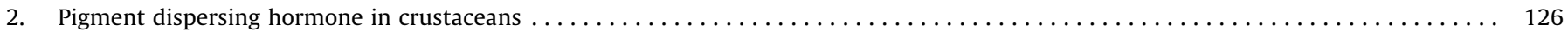

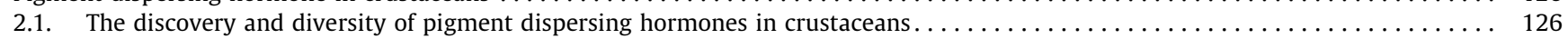

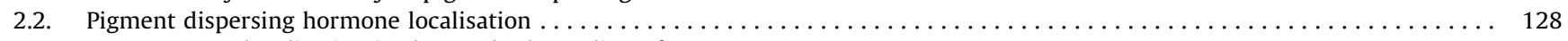

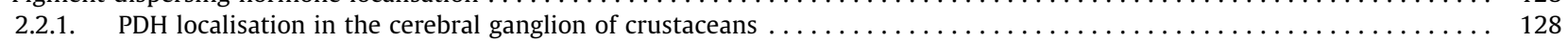

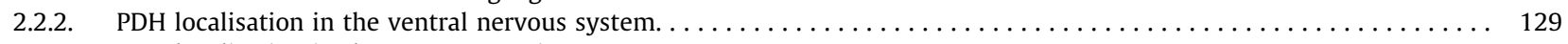

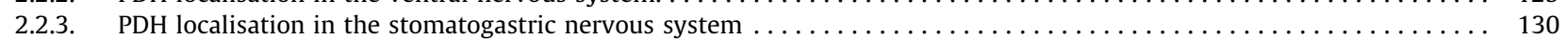

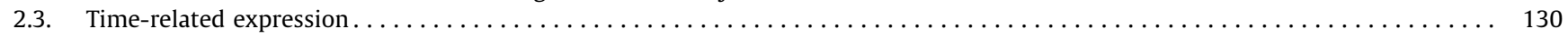

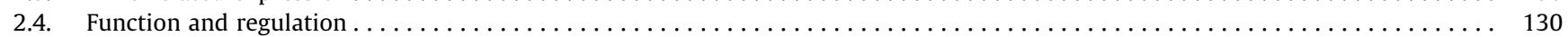

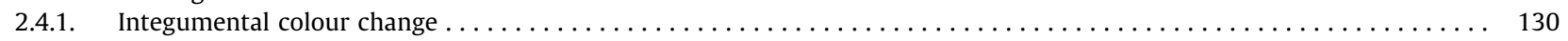

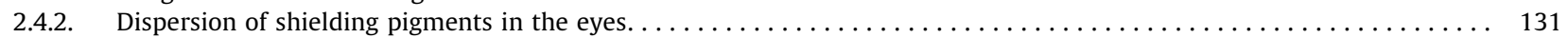

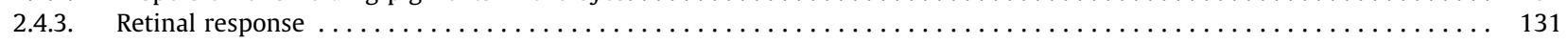

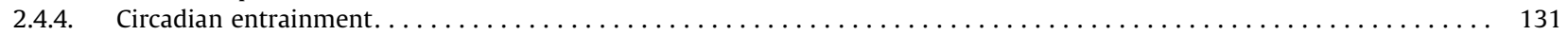

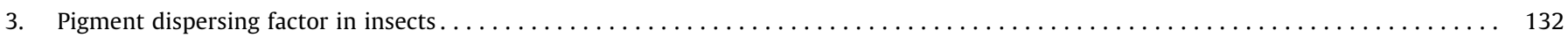

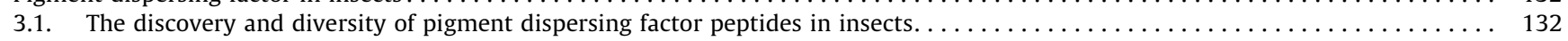

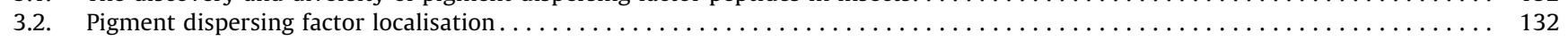

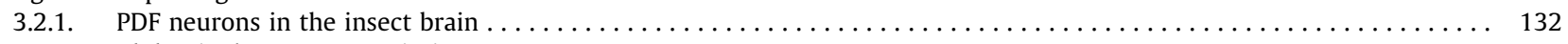

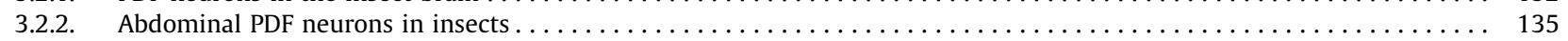

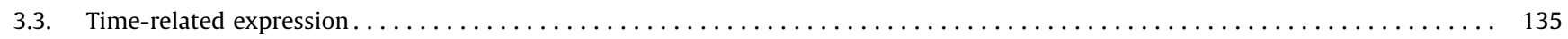

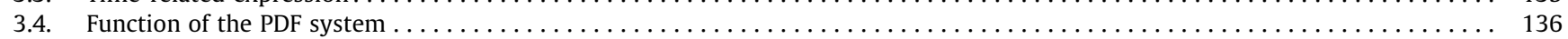

\footnotetext{
Abbreviations: AKH, adipokinetic hormone; aMe, accessory medulla; AVP, arginine vasopressin; BPN, brain photoreceptor neuropil; BPR, brain photoreceptor; COG, circumoesophageal ganglion; CT, circadian time; DD, continuous darkness; DH31, diuretic hormone 31; DN, dorsal neurons; DRPH, distal retinal pigment hormone; EM, external medulla; L, lamina ganglionaris; LAH, light-adapting hormone; LD, light-dark cycles; LL, continuous light; l-LNvs, large ventrolateral neurons; LNd, dorsolateral neurons; LNv, ventrolateral neurons; Lo, lobula; PACAP, pituitary adenylate cyclase-activating peptide; PDF, pigment dispersing factor; PDFAb, abdominal PDF neurons; PDFCa, PDF calyx neurons; PDF-ir, PDF immunoreactive/immunoreactivity; PDFLa, PDF lamina cells; PDFMe, PDF medulla cells; PDFR, PDF receptor; PDH, pigment dispersing hormone; PDH-ir, PDH immunoreactive/immunoreactivity; PTTH, prothoracicotropic hormone; RPCH, red pigment concentrating hormone; SCN, suprachiasmatic nuclei; SG, sinus gland; s-LNvs, small ventrolateral neurons; STNS, stomatogastric nervous system; TeTxLC, tetanus-toxin light chain; TM, terminal medulla; VIP, vasoactive intestinal peptide; VNC, ventral nerve cord; XO, X-organ.

* Corresponding author. Tel.: +32 16 324260; fax: +32 16323902 .

E-mail address: Liliane.schoofs@bio.kuleuven.be (L. Schoofs).

${ }^{1}$ These authors contributed equally to this work.
} 


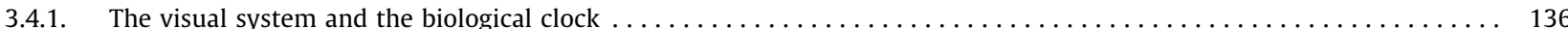

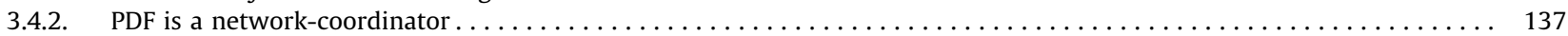

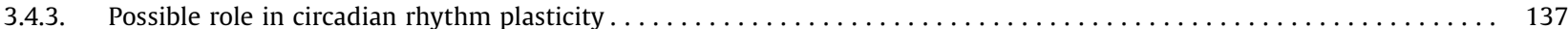

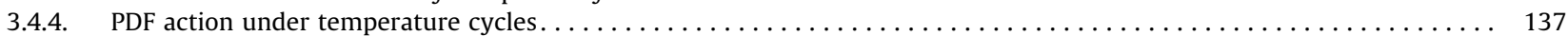

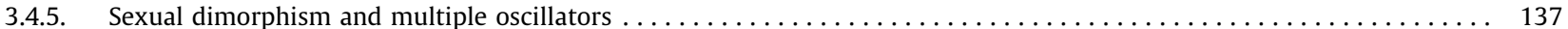

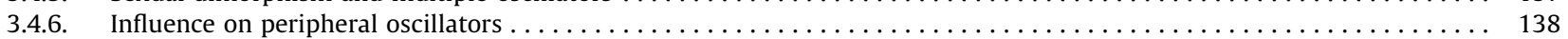

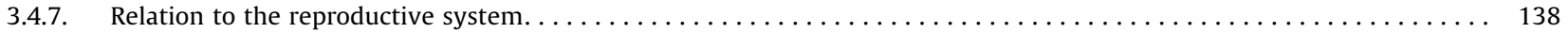

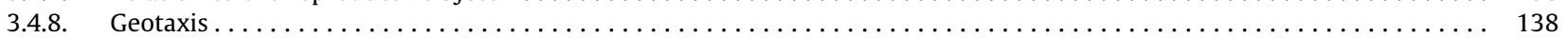

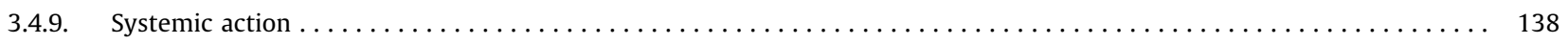

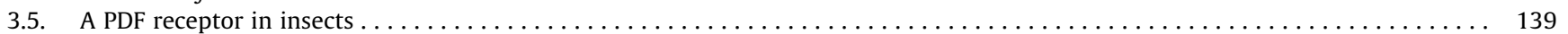

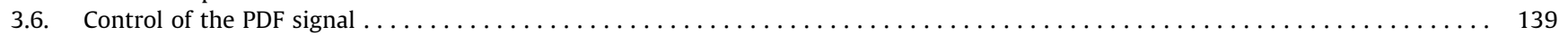

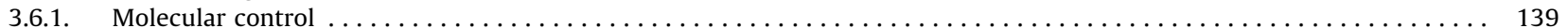

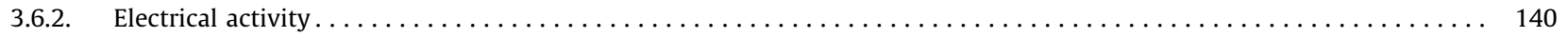

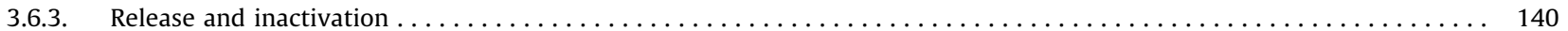

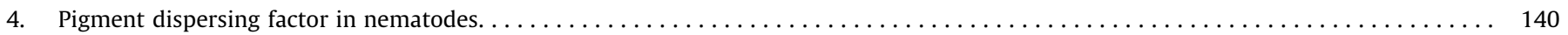

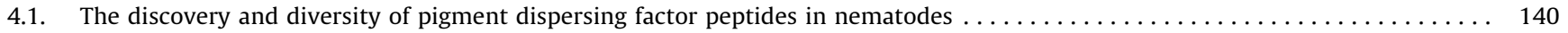

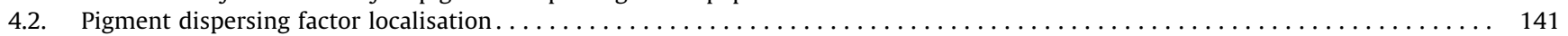

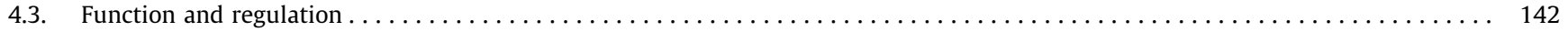

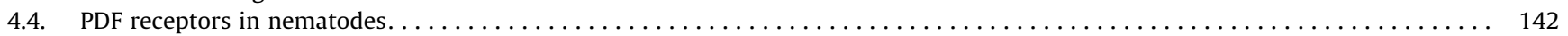

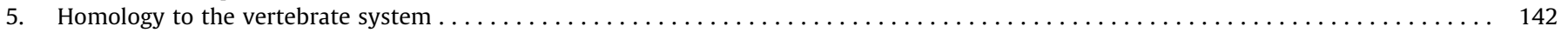

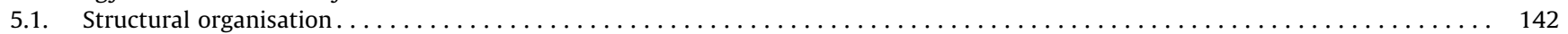

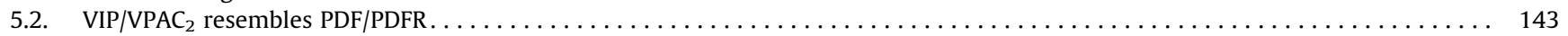

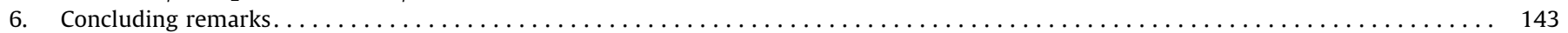

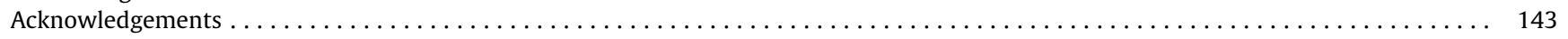

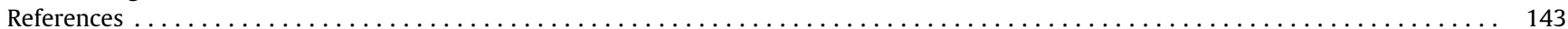

\section{Introduction}

Pigment dispersing hormone (PDH) and pigment dispersing factor (PDF) neuropeptides are conserved in a broad range of crustaceans, insects and nematodes.

In both Drosophila melanogaster and Caenorhabditis elegans, these peptidic ligands couple to class B (secretin type) $G$ protein-coupled receptors (Mertens et al., 2005; Hyun et al., 2005; Lear et al., 2005b; Janssen et al., 2008). Both PDF and PDH are thought to be present throughout an invertebrate's life, as they are detected from the embryonic stages on, into adulthood. For crustaceans as well as for insects, the PDH/PDF-system is invariably associated with the visual system. Hence, it is not surprising that the expression levels are usually related to the changing light conditions in the environment.

In crustaceans, PDH is involved in colour changes related to the pigment dispersion of integumental pigments and shielding pigments in the compound eye. PDH also seems to be involved in regulating the sensitivity of the electrical response to photic stimulation. PDF, on the other hand, serves as an important network coordinator and output factor in the insect circadian clock. It may even regulate the plasticity of this system, as has been reported for social insects (Bloch et al., 2003). In insects, this neuropeptide is widely studied and additional functions in activity, reproduction, arousal and geotaxis have been proposed. The PDFsignal is regulated in various ways, thereby taking advantage of molecular as well as electrical signals (Nitabach et al., 2006; Miśkiewicz et al., 2008; Wu et al., 2008a). In nematodes, this neuropeptide is mainly expressed in neurons that play a role in the sensing and integration of environmental stimuli. The exact function of PDF in this phylum remains elusive; although it was shown to influence locomotor behaviour (Janssen et al., 2008, 2009). While the invertebrate PDF receptor has a clear orthologue in vertebrates, i.e. the $\mathrm{VPAC}_{2}$ receptor, there is no clear conservation regarding the respective ligand sequences. It is nevertheless generally assumed that the functional homologue of PDF in vertebrates is vasoactive intestinal peptide, which also plays a role in the biological clock (Aton and Herzog, 2005; Vosko et al., 2007).

Here, we discuss the discovery and diversity, localisation, timerelated expression, functions and receptors of the different pigment dispersing hormone-like peptides.

\section{Pigment dispersing hormone in crustaceans}

\subsection{The discovery and diversity of pigment dispersing hormones in} crustaceans

Already in 1925, the first evidence for hormones that control rapid colour changes were provided by Koller (1925, 1927). Hemolymph from a dark coloured shrimp (Crangon crangon) was injected into a pale one and darkening, caused by pigment dispersion, was observed soon after injection. The eyestalks turned out to be the source of this substance (Perkins, 1928). A few decades later, the complete amino acid sequence of the first pigment dispersing and light-adapting hormone was reported from the eyestalks of $P$. borealis. It was named light-adapting distal retinal pigment hormone (DRPH) (Kleinholz, 1975; Fernlund, 1976). Because DRPH also controls the epidermal pigment migration in cells of many other crustacean species, this octadecapeptide is now referred to as pigment dispersing hormone (PDH) (Rao and Riehm, 1993). Peptides with similar sequences (Table 1 ) are nowadays referred to as $\alpha-\mathrm{PDH}$ as to distinguish them from a second peptide with pigment dispersing abilities identified from the eyestalks of the fiddler crab Uca pugilator (Rao et al., 1985). The sequence of this $U$. pugilator peptide differs from $\alpha-\mathrm{PDH}$ at six positions and was designated $\beta$-PDH (Table 1 ). Additional isoforms of $\alpha$ - and $\beta-P D H$ were identified afterwards and can all be grouped as $\alpha$ - or $\beta$-PDH subfamily members based on their amino acid sequence, acidity and charge similarity. The most important differences in amino acid sequence are the Gly and Met in $\alpha-\mathrm{PDH}$ at position three and four whereas $\beta$-PDH contains Glu followed by Leu causing it to be more potent than $\alpha-\mathrm{PDH}$. Until to date, $\alpha-\mathrm{PDH}$ has only been found in species of the genus Pandalus and Macrobrachium while $\beta-P D H$ could be identified in a wide variety of crustaceans (Rao et al., 1987; Rao and Riehm, 1993; Park and Hall, 1998; Rao, 2001).

Like most neuropeptides, mature PDH originates from a larger precursor molecule. The PDH precursor contains a signal peptide, followed by a poorly conserved PDH precursor related peptide of unknown function and at the end of the open reading frame, the mature PDH flanked by either mono- or dibasic processing sites (Klein et al., 1992, 1994; De Kleijn et al., 1993; De Kleijn and Van Herp, 1995; Desmoucelles-Carette et al., 1996, 1998; Rao, 2001; 
Table 1

Sequence alignment of crustacean PDH peptides. Identical amino acids are highlighted in black, conserved amino acids in dark gray. X=I or L.

\begin{tabular}{|c|c|c|}
\hline Species & Peptide sequence & Reference \\
\hline \multicolumn{3}{|l|}{ Crustacean $\alpha-\mathrm{PDH}$} \\
\hline Macrobrachium rosenbergii & NSGMINSILGIPKVMAEAamide & (Rao, 2001) \\
\hline Pandalus jordani-III & NSGMINS ILGIPKVMADAamide & (Rao and Riehm, 1989) \\
\hline Pandalus borealis & NSGMINSILGIPRVMTEAamide & (Fernlund, 1976) \\
\hline Pandalus jordani-II & NSGMINSILGIPRVMTEAamide & (Rao and Riehm, 1989) \\
\hline \multicolumn{3}{|l|}{ Crustacean $\beta$-PDH } \\
\hline Cancer borealis-II & NSELINSLLGISRLMNEAamide & (Ma et al., 2009b) \\
\hline Cancer productus-II & NSELINSLLGLSRLMNEAamide & (Fu et al., 2005b; Hsu et al., 2008; Hsu et al. 2010) \\
\hline Callinectus sapidus-II* & NSELINSLLGISALMNEAamide & (Klein et al., 1994) \\
\hline Pacifastacus leniusculus & NSELINSILGLPKVMNDAamide & (Rao and Riehm, 1993) \\
\hline Uca pugilator & NSELINSILGLPKVMNDAamide & (Rao et al., 1985) \\
\hline Neohelice granulata & NSELINSILGLPKVMNDAamide & n.d. \\
\hline Carcinus maenas & NSELINSILGLPKVMNDAamide & (Klein et al., 1992; Lohr et al., 1993; Ma et al., 2009a) \\
\hline Cancer productus-I & NSELINS ILGLPKVMNDAamide & (Fu et al., 2005b; Hsu et al., 2008) \\
\hline Cancer magister & NSELINSILGLPKVMNDAamide & (Kleinholz et al., 1986) \\
\hline Cancer borealis-I & NSELINSILGLPKVMNDAamide & (Ma et al., 2009b) \\
\hline Callinectes sapidus-I & NSELINSILGLPKVMNDAamide & (Klein et al., 1994; Mohrherr et al., 1990) \\
\hline Astacus leptodactylus & NSEXXNSXXGXPKMNDAamide & own unpublished results \\
\hline Orconectes immunis & NSELINSILGLPKVMNEAamide & (Rao and Riehm, 1993) \\
\hline Orconectes limosus & NSELINSILGLPKVMNEAamide & (Bulau et al., 2004; DeKleijn et al., 1993) \\
\hline Procambarus clarkii & NSELINSILGLPKVMNEAamide & (McCallum et al., 1991) \\
\hline Litopenaeus vannamei-B & NSELINSLLGLPKVMNDAamide & (Desmoucelles-Carette et al., 1996; Ohira et al., 2006) \\
\hline Penaeus japonicus-I & NSELINSLLGIPKVMTDAamide & (Ohira et al., 2002; Yang et al., 1999) \\
\hline Pandalus jordani-I & NSELINSLLGLPKVMTDAamide & (Rao and Riehm, 1989) \\
\hline Penaeus japonicus -II & NSELINSLLGLPKFMIDAamide & (Ohira et al., 2002; Yang et al., 1999) \\
\hline Litopenaeus vannamei-A & NSELINSLLGIPKVMNDAamide & (Desmoucelles-Carette et al., 1996; Ohira et al., 2006) \\
\hline Penaeus aztecus & NSELINSLLGIPKVMNDAamide & (Phillips et al., 1988 fide Rao and Riehm, 1989) \\
\hline Armadillidium vulgare & NSELINSLLGAPRVLNNAamide & (Rao and Riehm, 1993) \\
\hline Daphnia pulex* & NSELINSLLGLPRFMKVVamide & (Gard et al., 2009) \\
\hline Orconectes limosus-B & NSELINAILGSPTLFGEVamide & (Bulau et al., 2004) \\
\hline Orconectes limosus-C & NSELINAILGSPTLMGEVamide & (Bulau et al., 2004) \\
\hline
\end{tabular}

*Amino acid sequence derived from cDNA precursor sequence (ClustalW2 and BOXSHADE 3.21).

Chuman et al., 2002; Ohira et al., 2002; Yamano and Unuma, 2006; Hsu et al., 2008; Gard et al., 2009). The amino acid sequence of various $\mathrm{PDH}$ peptides in crustaceans turned out to be largely identical which results in biological cross-reactivity. Bioassays like the injection of fractionized eyestalk extracts (Rao et al., 1985, 1987) to induce pigment dispersion in eyestalkless crabs provided a good start for the discovery of chromatophorotropin-like peptides. Applications like multi-dimensional HPLC separations, more advanced mass spectral techniques and the construction and screening of EST databases contributed to an even more extended list of PDH peptides in crustaceans. Crustaceans including Callinectes sapidus, Cancer productus, Litopenaeus vannamei (also known as Penaeus vannamei), Penaeus japonicus (also known as Marsupenaeus japonicus), Orconectes limosus and Pandalus jordani turned out to express multiple forms of $\beta$-PDH or even both $\alpha$ - and $\beta$-PDH as in the case of P. jordani (Rao and Riehm, 1989, 1993; Mohrherr et al., 1990; De Kleijn et al., 1993; Klein et al., 1994; Desmoucelles-Carette et al., 1996; Yang et al., 1999; Rao, 2001; Ohira et al., 2002, 2006; Bulau et al., 2004; Fu et al., 2005a,b; Hsu et al., 2008). The kuruma prawn $P$. japonicus expresses two different $\beta$-PDH peptides. They were initially purified from sinus gland (SG) extracts and bioassays showed that both peptides were able to cause pigment dispersion in all four types of chromatophores. Pej-PDH-II showed to be almost ten-fold more potent than Pej-PDH-I for erythrophores, xanthophores and melanophores. Erythrophores and xanthophores were the most sensitive of the four chromatophores (Yang et al., 1999). Fu and co-workers revealed the presence of two distinct $\beta$-PDH peptides in C. productus (Fu et al., 2005b). Molecular cloning of the cDNAs revealed one transcript (prepro- $\beta$-pdh I) encoding the authentic $\beta$-PDH (NSELINSILGLPKVMNDAamide; Rao et al., 1985), from then on referred to as $\beta$-PDH I. Two other transcripts were both found to encode a second peptide, NSELINSLLGLSRLMNEAamide, from then on called $\beta$-PDH II (Hsu et al., 2008, 2010). These cDNAs encoded distinct PDH-precursor-related peptides and were therefore named prepro- $\beta$-pdh IIa and prepro- $\beta$-pdh IIb. The presence of multiple PDH peptides raises the question whether or not this is a way to create a redundant PDH system or whether the peptides have different functions. Double in situ hybridisation and direct tissue mass spectrometry suggested that the two isoforms have distinct functions. While only Canpr- $\beta$-PDH II was detected in the neurosecretory SG, indicating that it acts as a neurohormone, Canpr- $\beta$-PDH I was found in all other parts of the eyestalk suggesting that it has a function as a local neuromodulator or neurotransmitter (Hsu et al., 2008) (see also Section 2.2.1). The C. productus $\beta$-PDH II is almost identical to $C$. sapidus $\beta$-PDH II except for position 11 and 13 (Table 1). Despite the sequence similarity, their functions are predicted to be different. As opposed to $C$. productus, $\beta$-PDH II in $C$. sapidus is thought to act as a local neurotransmitter/modulator and $\beta$-PDH I is found in the SG indicating that it acts as a neurohormone (Klein et al., 1994). These hypothetic functions based on localisation represent the only attempts to clarify the presence of multiple PDH peptides in one species.

Two of the three 0 . limosus $\beta$-PDH peptides (PDHB and PDHC) distinguish themselves from the other known crustacean $\beta$-PDH peptides with a Val at the C-terminus instead of an Ala (Bulau et al., 2004) (Table 1). Recently, the Daphnia pulex PDH precursor could be identified by means of an in silico analysis of an EST database. $D$. pulex $\mathrm{PDH}$ is predicted to also have a Val as a C-terminal amino acid (Gard et al., 2009). The biological function of this distinct structure unfortunately remains elusive.

Small variations in amino acid sequence can cause significant changes in potency of the peptides depending on the position of the amino acids. By testing different forms of PDH in the $U$. pugilator pigment dispersion bioassay, it can be concluded that the two substitutions at position eight and eleven are not critical for $\mathrm{PDH}$ potency. On the contrary, positions three, four and seventeen 
influence PDH potency significantly since $\alpha$-PDH with Gly and Met at positions three and four respectively is less potent than $\beta$-PDH. Substitution of Leu at position four by Ile does not prevent receptor activation as insect PDH-like peptides like the Romalea microptera PDF are able to induce pigment dispersion in U. pugilator (Rao et al., 1987). Although it seems that especially the N-terminal part of the peptide is critical for its potency, Glu at position 17 instead of Asp causes a significant decrease in potency in the crustacean bioassay (Rao and Riehm, 1989) (Table 1).

Although a vast collection of different PDH-peptides have been synthesised and tested, and the effects and the potencies of these peptides have been studied thoroughly, there is still a lack of knowledge concerning the actual PDH receptor(s) and cellular pathway(s) involved in pigment dispersion. A single mRNA and derivative amino acid sequence of a predicted PDH receptor in $P$. japonicas is known without any additional information (GenBank $\mathrm{AB} 478163.1$ ). It has been suggested that $\mathrm{PDH}$ signalling comprises adenylate cyclase, cAMP and protein kinase A (Nery and Castrucci, 2002).

\subsection{Pigment dispersing hormone localisation}

When synthetic $\alpha$ - and $\beta$-PDH became available for the production of antibodies, immunocytochemical PDH localisations were conducted (Schueler et al., 1986; Dircksen et al., 1987). Since PDH was known to be an eyestalk hormone, localisation studies were initially carried out in the optic ganglia of the eyestalks. Shortly after, PDH-immunoreactive (PDH-ir) structures in other regions of the cerebral ganglion (also known as the brain or supraoesophageal ganglion) and in the ventral nerve cord (VNC) and stomatogastric nervous system (STNS) were explored (Mangerich and Keller, 1988; Mortin and Marder, 1991). It turned out that the majority of PDH-ir cells and fibers are located in the eyestalks and the median protocerebrum (as is also the case for insects as described in Section 3.2).

Sequentially, we will discuss PDH localisation in the cerebral ganglion (optic ganglia and median protocerebrum), the VNC and the STNS.

\subsubsection{PDH localisation in the cerebral ganglion of crustaceans}

In general, the decapod brain consists of three regions called the protocerebrum, deuterocerebrum, and tritocerebrum, all with a very complex internal organisation of neuropil regions and tracts (Fig. 1A). PDH localisation is particularly observed in the protocerebrum which consists of the optic ganglia, lateral protocerebrum and median protocerebrum. Among neuropil regions in the eyestalks, are the lamina ganglionaris $(\mathrm{L})$, external medulla (EM) and lobula (Lo) (Fig. 1A). Another neuropil of interest regarding PDH localisation is the terminal medulla (TM) in the lateral protocerebrum. The median protocerebrum contains the protocerebral bridge, central body, posterior medial protocerebral neuropil and the anterior medial protocerebral neuropil which is connected to the TM through the protocerebral tract (also known as the optic nerve or optic tract) (Sandeman et al., 1992; Böhm et al., 2001; Kirby and Nusbaum, 2007).

$\alpha$-PDH immunoreactive structures are specifically observed in the eyestalks of Pandalus species. $\alpha$-PDH-ir is co-localised with $\beta$-PDH-immunoreactivity ( $\beta-\mathrm{PDH}-\mathrm{ir})$ in Pandalus danae eyestalks (Phillips et al., 1990). Actually, the majority of PDH-ir studies have been carried out with $\beta$-PDH antibodies and detailed descriptions of $\beta$-PDH-ir in the brains of Carcinas maenas, Cancer productus, Cherax destructor, Orconectus limosus, Homarus americanus, Cancer pagurus and U. pugilator are now available (Mangerich et al., 1987; Dircksen et al., 1987; Hsu et al., 2008; Harzsch et al., 2009). The most striking similarities are the putative innervation of the neurohemal SG by neurons located between the Lo and the TM as seen in Astacurans as well in Brachyuran species (Fig. 1B and D) together with $\beta-\mathrm{PDH}-\mathrm{ir}$ in the median protocerebrum (Fig. 1C).

$\beta$-PDH localisation studies in Astcuran species were conducted in Procamburus clarkii, Cancer destructor, Homarus americanus and $O$. limosus (Mangerich et al., 1987; Dircksen et al., 1987; Mangerich and Keller, 1988; De Kleijn et al., 1993; Sullivan et al., 2009; Harzsch et al., 2009). Harzsch and colleagues nicely illustrate $\beta$-PDH-ir in eyestalks, median protocerebrum and VNC (see Section 2.2.2) in the lobster H. americanus (Harzsch et al., 2009). The $\beta$-PDH-ir pattern in the eyestalks of $H$. americanus consists of intense labelling of somata between the EM and TM, fiber networks in the EM and TM and fibers terminating in the SG (Fig. 1B). A clear bundle of fibers runs from the somata ( $\mathrm{C}, \mathrm{C}^{\prime}$ and $\left.\mathrm{C}^{\prime \prime}\right)$ between the EM and TM towards the TM and leaves the eyestalk towards the median protocerebrum via the protocerebral tract. The same somata also seem to have axons that enter the sinus gland (SG) and additionally extend their axons to form fiber networks in the EM. Some other somata (A and B) associated with the TM also send their axons to the median protocerebrum through the protocerebral tract. Some of the axons running from the eyestalks to the median protocerebrum continue their path around the oesophagus and towards the VNC (not shown). Additionally there are two pairs of $\beta$-PDH-ir somata located in the anterior part of the median protocerebrum and two other large labelled somata between the protocerebral plexus which shows $\beta$-PDH-ir and the posterior medial protocerebral neuropil (without PDH-ir) (Harzsch et al., 2009).

$P$. clarkii as well as $C$. destructor, shows intense characteristic $\beta$ $\mathrm{PDH}$-ir in the anterior regions of the median protocerebrum. In both species, there are also large, paired $\beta$-PDH-ir somata in Cluster 6 which extend posteriorly through the brain and into the circumoesophageal connectives. In $C$. destructor, the most intense $\beta-\mathrm{PDH}-\mathrm{ir}$ is found in the brain photoreceptor neuropils (BPNs) (Fig. 1C). The BPNs are innervated by axons extending from the extraretinal brain photoreceptor (BPR) which is not $\beta$-PDH-ir. Interestingly, as described in more detail in Sections 2.3 and 2.4.4, expression of $\beta-\mathrm{PDH}$ in these regions of the brains of both $P$. clarkii and $C$. destructor varies during the day (Sullivan et al., 2009).

$\beta$-PDH expressing cells in the eyestalks of 0 . limosus are also located at the transition of the Lo and TM. The X-organ (XO) contained only two or three cells, which are probably of minor significance. In addition, small perikarya in the proximal part of the $\mathrm{L}$ were found by immunocytochemistry. This might be a result of cross-reaction, since these cells were not found by cRNA probes (De Kleijn et al., 1993). Again, several somata with $\beta$-PDH-ir were located in the anterior part of the median protocerebrum, sending axons towards the optic neuropil and into the eyestalk (Mangerich and Keller, 1988).

PDH localisation in the nervous system of Brachyurans is most extensively studied in the crab $C$. productus and moreover, $\beta$-PDHir was varified by in situ hybridisation with isoform specific riboprobes and mass spectromity. Since $\beta-\mathrm{PDH}$-ir in $C$. productus is similar to that in other Brachyurans, we will only discuss $\beta-P D H$ localisation in the Brachyuran C. productus (Hsu et al., 2008).

The eyestalk ganglia of $C$. productus contain several $\beta$-PDH-ir somata in the L, between the Lo and TM and in the XO (Fig. 1D). Somata between the Lo and TM give rise to axons that innervate neuropils in the EM, Lo and TM and some also arborize within the SG. It is not clear what parts are innervated by axons departing from the $\beta$-PDH-ir somata in the XO but it is clear that it is not the SG. In the median protocerebrum, intense $\beta$-PDH-ir could be detected in two somata of Cluster 6 . These project to and ramify in the optic neuropil in the median protocerebrum and travel through the optic nerve to the TM. One fiber travels from the optic neuropil to both circumoesophageal connectives of the STNS (see Section 2.2.3) (Hsu et al., 2008). 

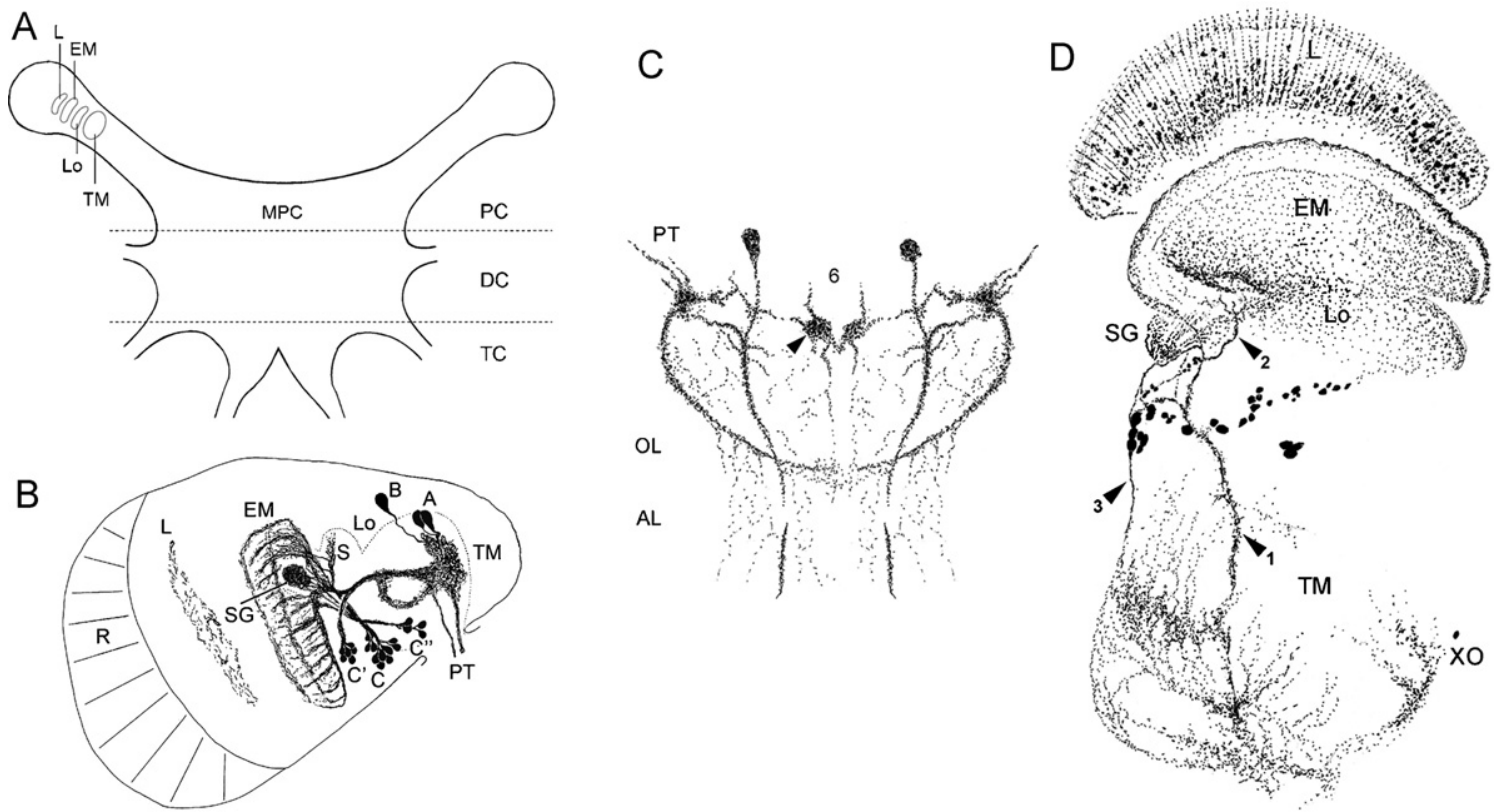

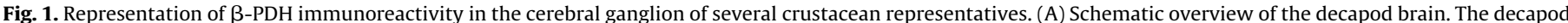

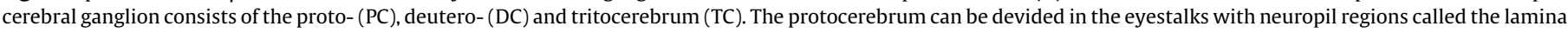

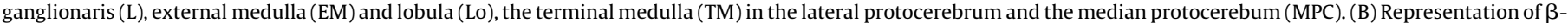

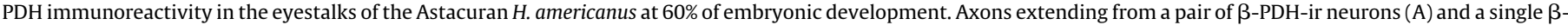

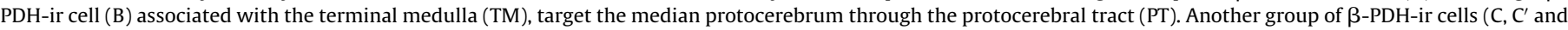

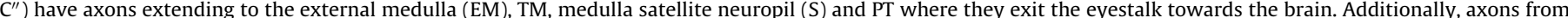

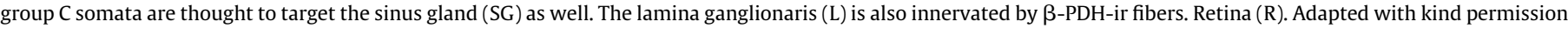

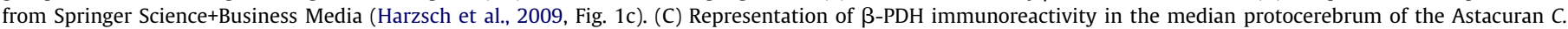

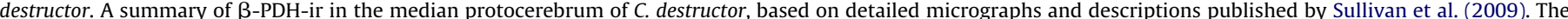

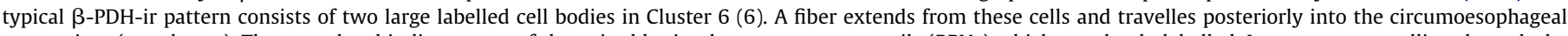

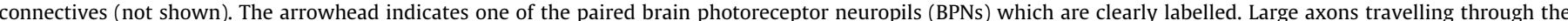

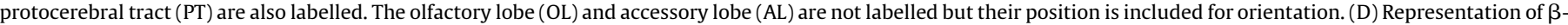

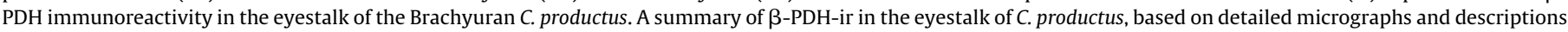

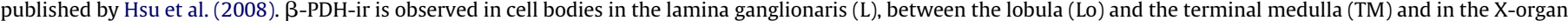

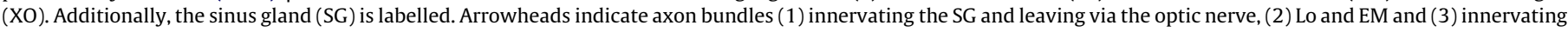
the SG and not travelling through the optic nerve.

Like several other crustaceans, $C$. productus expresses more than one PDH isoform (Table 1) (Fu et al., 2005b; Hsu et al., 2008). In order to distinguish between the two isoforms of $C$. productus and confirm the results of the antibody staining, double in situ hybridisation with riboprobes was carried out to localise prepro$\beta$-pdh I and II mRNA. Prepro- $\beta$-pdh I mRNA was indeed found in the cell bodies of the L, a cluster of cell bodies between the Lo and TM and in the XO. Prepro- $\beta$-pdh II mRNA was found in other Lo/TM cell bodies and a single XO cell body where it is co-localised with prepro- $\beta$-pdh I, but not in the L (Hsu et al., 2008).

Finally, Matrix-assisted laser desorption/ionisation Fourier transform mass spectrometry (MALDI-FTMS) was used to analyze several eyestalk tissues of $C$. productus. This resulted in a positive identification of $\beta$-PDH I in the L, EM, Lo, TM and XO. $\beta$-PDH II on the other hand, was specifically localised in the SG suggesting that C. productus $\beta-\mathrm{PDH}$ II can act as a neurohormone. $C$. productus $\beta$ PDH I is however thought to act as a local neurotransmitter and/or modulator (Hsu et al., 2008).

So far, PDH expression patterns have mostly been studied in the adult nervous system of crustaceans. Surprisingly, most of the PDH-positive structures in adult animals can already be found in early embryological stages as was shown in the Astacuran $H$ americanus (Harzsch et al., 2009). Unfertilised Carcinus maenas oocytes showed that PDH is expressed from maternally derived PDH mRNA during embryonic development. Immunocytochemical experiments showed that the peptide appears as soon as one to two days after the onset of eye formation (when the embryo is already developed for about 50\%). The functional significance of the early PDH presence remains elusive but the authors suggest it may point to circadian clock-driven processes in the embryo (Chung and Webster, 2004; Harzsch et al., 2009).

Some species exhibit either PDH expression in the eyestalks or the median protocerebrum. For example in the pandalid $P$. japonicus, RT-PCR demonstrated that PDH expression was only present in the eyestalk and not in the brain, thoracic ganglia, abdominal ganglia, hindgut and hepatopancreas (Ohira et al., 2002). PDH-like staining within the CNS of the copepod crustacean Calanus finmarchicus with an antibody against $U$. pugilator $\beta-\mathrm{PDH}$ (Dircksen et al., 1987) is limited to one pair of somata in the protocerebrum and the axonal projections emanating from them (Sousa et al., 2008).

\subsection{2. $P D H$ localisation in the ventral nervous system}

$\mathrm{PDH}-\mathrm{ir}$ in the ventral nervous system is generally less pronounced compared to the eyestalks and median protocerebrum.

The ventral nervous systems of the Astacurans $O$. limosus and $H$. americanus show similar PDH-ir (Mangerich and Keller, 1988; Harzsch et al., 2009). Fibers extending from the protocerebrum reach the circumoesophageal ganglia (COGs) through the circumoesophageal connectives. PDH-ir positive perikarya are found in the suboesophageal ganglion of $O$. limosus but PDH could not be located in the thoracic or abdominal ganglia. Axons showing PDHir travel towards the caudal end of the VNC with extensive branching in all thoracic and abdominal ganglia. Similarly in $H$. americanus, large medial PDH-ir somata in the median protocer- 
ebrum of $H$ americanus send axons towards the VNC via the circumoesophageal connectives together with neurites extending from the eyestalks (Section 2.2.2). Branching of these axons results in a plexus with PDH-ir in the COGs. More posteriorly, PDH-ir is observed throughout the entire VNC with extensive branching in the ganglia of the VNC (Harzsch et al., 2009).

In the Brachyuran C. maenas, $\mathrm{PDH}$-ir in the $\mathrm{VNC}$ is different as the ventral ganglia are differently organised (Mangerich and Keller, 1988). C. maenas contains more somata with PDH-ir in its condensed thoracic ganglion with their axons forming a plexus in the posterior part of the thoracic ganglion (Mangerich and Keller, 1988).

\subsubsection{PDH localisation in the stomatogastric nervous system}

The STNS of crustaceans consists primarily of the interconnected stomatogastric ganglion, oesophageal ganglion and the paired commissural ganglia (COGs) and motor neurons innervating the muscles of the stomach (Fig. 2). It generates rhythmic motor patterns responsible for moving, chewing and filtering food particles (Christie et al., 2010).

Mortin and Marder characterised $\beta$-PDH distribution in the Palinuran Panulirus interruptus, the Astacurans H. americanus and $P$. clarkii and the Brachyurans $C$. borealis and $C$. antennarius by using an antibody raised against $\beta$-PDH from $U$. pugilator (Dircksen et al., 1987; Mortin and Marder, 1991). In all five species, $\beta$-PDH-ir somata, neuropils and fibers were observed in the COGs though in different positions within the COG (Fig. 2). Additional PDH-ir localisation varied among the different species and sometimes also between the more closely related species as is the case with $C$. borealis and $C$. antennarius. $C$. antennarius is the only species who exhibited PDH-ir structures in the oesophageal ganglion and inferior oesophageal nerve. In C. antennarius, six neurons located in the COGs were PDH-ir. Of these, two were cross-connecting the two COGs, indicating a possible function as bilateral communicators. Two homologous PDH-ir cells were identified in C. borealis but the crossing PDH-ir fibers were absent. Two other Brachyuran species, $C$. productus and $C$. sapidus, show similar distribution of PDH-ir in the STNS but without the cross-connecting fibers in the OG and ion (Hsu et al., 2008).

$P$. interruptus showed a high concentration of PDH-ir fibers in the neuropil region of the stomatogastric ganglion, originating from the COG. This intensive staining of neuropil synapses suggests a local modulatory function of PDH in the stomatogastric ganglion. $H$. americanus and $P$. clarkii showed extremely faint staining in the neuropil region of the stomatogastric ganglion. Several other neuropeptides proved to modulate the rhythmic motor patterns generated by the stomatogastric ganglion but it still remains unclear if PDH is biologically active in the STNS (Christie et al., 2010; Mortin and Marder, 1991).

\subsection{Time-related expression}

PDH in crustaceans is released upon illumination. Additionally, experiments with Procambarus bouvieri showed that a circadian rhythm of PDH concentration in the nervous system persists under constant dark conditions (Aréchiga and Mena, 1975). Recently, the intensity of PDH-ir in the brains of $C$. destructor and P. clarkii was shown to be in phase with their locomotor activity rhythms (Sullivan et al., 2009). Both crayfish are more active during the night compared to the day, but show distinct peaks of activity. Without anticipation, $C$. destructor rapidly increases its activity level with the onset of darkness, followed by a gradual decrease of activity towards the onset of day. P. clarkii shows two distinct peaks of activity: one at the onset of darkness and one before the beginning of the day. PDH expression in Cluster 6 cell bodies in $C$. destructor follows the activity pattern by increasing almost twofold after the onset of darkness, followed by a gradual decrease over the next 7-8 h. PDH expression in the BPNs of P. clarkii also matches the specific activity pattern with a significant increase preceding both night and day (see also Section 2.4.4, circadian entrainment) (Sullivan et al., 2009).

\subsection{Function and regulation}

\subsubsection{Integumental colour change}

Colour change is a phenomenon observed in many crustaceans and has been studied for more than a century. Colour changes can be brought about by the multiplication of chromatophores. These are specialised pigment-bearing cells with branched cytoplasmatic processes. In crustaceans, there are four types of chromatophores: erythrophores, xanthophores, leukophores and melanophores, containing respectively red, yellow, white and black or brown granules (Fingerman, 1970; Josefsson, 1983). Most of them are part of the integument and are located in the connective tissue below the epidermis. Slow colour changes can be observed in areas with a transparent or thin exoskeleton. Division of the chromatophores causes the total amount of pigment to increase and results in a darker colour. However, rapidly reversible integumental colour changes are brought about solely by intracellular concentration or dispersion of pigment granules. Among crabs, colouration may vary in function of social behaviour such as mating or as a result of e.g. background colour, temperature, stress or moulting (e.g. Little, 1967; Takeda, 2006; Silbiger and Munguia, 2008; Detto et al., 2008). The best studied colour change is the endogenous mechanism that especially fiddler crabs (Uca) use, to darken during the day and lighten at night. The darker colour acts as a natural sunscreen, providing protection against intense sunlight during the day. For example, melanophores and erythrophores of $U$. pugilator, $U$. rapax and $U$. maracoani and melanophores of $U$. pugnax, $U$. mordax and to a much lesser extent $U$. thayeri, continue to alternate dispersing and concentrating their pigments under constant darkness (Brown, 1950; Hines, 1954; Barnwell, 1963; Thurman, 1988). Apart from these Uca species, the blue crab C. sapidus and the crab Neohelice granulata (formerly known as Chasmagnathus granulatus) also show persistent rhythms of pigment migration in melanophores (Fingerman, 1955; Granato et al., 2004).

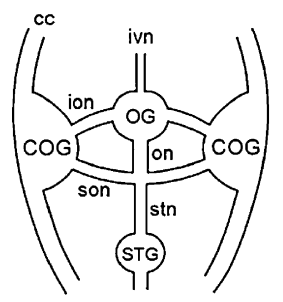

\begin{tabular}{|c|c|c|c|c|c|c|c|c|c|c|c|c|}
\hline & \multicolumn{2}{|c|}{ Somata } & \multicolumn{4}{|c|}{ Neuropils } & \multicolumn{6}{|c|}{ Fibers } \\
\hline & $\mathrm{COG}$ & son & COG & STG & stn & on/son/stn & COG & OG & $\mathrm{cc}$ & ion & son & stn \\
\hline Panulirus interruptus & $x$ & $x$ & $x$ & $x$ & $x$ & $\mathrm{x}$ & $x$ & & $x$ & & $x$ & $x$ \\
\hline $\begin{array}{l}\text { Homarus americanus } \\
\text { Procambarus clarkii }\end{array}$ & $\begin{array}{c}\text { faint } \\
x\end{array}$ & & $\begin{array}{l}x \\
x\end{array}$ & $\begin{array}{l}\text { faint } \\
\text { faint }\end{array}$ & & & $\begin{array}{l}x \\
x\end{array}$ & & $\begin{array}{l}x \\
x\end{array}$ & & $x$ & $x$ \\
\hline Cancerborealis & $x$ & & $\mathrm{x}$ & & & & $x$ & & $x$ & & & \\
\hline Cancerantennarius & $x$ & & $x$ & & & & $x$ & $\mathrm{x}$ & $x$ & $\mathrm{x}$ & & \\
\hline Cancerproductus & $x$ & & $x$ & & & & $x$ & & $x$ & & & \\
\hline
\end{tabular}

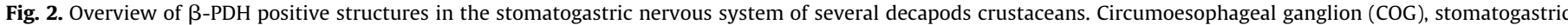

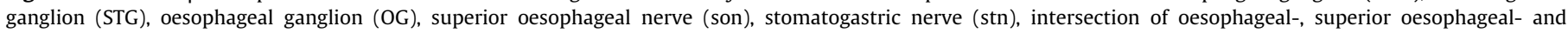
stomatogastric nerve (on/son/stn), circumoesophageal connective (cc), inferior oesophageal nerve (ion). 
The origin of this endogenous rhythm can be found in the cyclic synthesis and release of RPCH and PDH. Granato and co-workers showed that the melanophores of $N$. granulata additionally respond to light itself. This primary response amplifies the black pigment dispersion in response to $\mathrm{PDH}$ and can be observed even when the PDH trigger is lost. Additionally, the responsiveness of the melanophores varies through the day, with a larger response to $\mathrm{PDH}$ during the day compared to the night (Granato et al., 2004).

\subsubsection{Dispersion of shielding pigments in the eyes}

Pigment movements also take place within the ommatidia of the compound eyes of crustaceans. These eyes contain an elaborate system of pigments for screening and reflection of light and are able to reversibly adapt to bright and dim light (Fig. 3) (reviewed by Meyer-Rochow, 2001). Decapod ommatidia typically contain a lens-shaped cornea that is part of the exoskeleton. Immediately below the cornea are two corneagenous cells which secrete the cornea. The crystalline cone below the corneagenous cells consists of four crystalline cells. Most decapods have superposition (darkadapted or nocturnal) eyes which are able to adjust their sensitivity, albeit to a limited extent, to bright light. In superposition eyes, the crystalline cone is connected to the light-sensitive rhabdome located at the base of the ommatidium by a cone stalk which transmits the light (Fig. 3). This rhabdome is actually a gathering of rhodopsin containing microvilli which arise from seven circular retinular cells. Light passing the cone stalk is able to reach neighbouring rhabdomes of other ommatidia which causes a blurred image but achieves a maximum detection of dim light. To be able to adapt to changing light intensities, the retinular cells contain granules with retinal shielding pigments called the proximal pigments. Two cells surrounding the crystalline cone and tracts of the ommatidia contain the so-called distal pigments. Additionally, Astacuran decapod crustaceans such as shrimps, crayfish, prawns and lobsters have reflecting pigments at the base of the ommatidia. Both the proximal and distal screening pigment granules can either be dispersed in a light-adapted position wherein they prevent the light rays from reaching neighbouring photo-sensitive rhabdomes, or they can be aggregated in a darkadapted position leaving the rhabdomes exposed to light (Fig. 3). In fact, these changes follow a circadian pattern (Bennitt, 1932b; Hernández-Falcón et al., 1987).

The migration of the proximal and distal pigment granules is controlled by distinct mechanisms. On one hand, the proximal pigment granules are able to quickly disperse without the presence of the SG as was shown in Cambarus and Procambarus (Kleinholz, 1949; Olivo and Larsen, 1978). Some authors have suggested though, that the cells containing the proximal pigments are also hormonally controlled (Bennitt, 1932a,b; Welsh, 1939; Fingerman et al., 1962). On the other hand, the circadian movement of the distal and reflecting pigment was shown to be under control of an eye-stalk hormone in Palaemonetes (Welsh, 1930; Kleinholz, 1934, 1936). This hormone turned out to be the same hormone that causes rapid integumental colour changes, i.e. PDH, also named light-adapting hormone (LAH) or distal retinal pigment hormone (DRPH) (Fernlund, 1976).

\subsubsection{Retinal response}

Not only does PDH influence the movement of the shielding pigments, it also seems to have several effects on the phototransduction process itself. Crustacean photoreceptor cells depolarise upon illumination. This can be recorded by means of an electrode penetrating the cell. In P. clarkii, exogenous applied PDH causes the amplitude of the depolarisation to diminish in an irreversible way. However, the amplitude of this effect depends on the circadian time suggesting a higher affinity or maybe more

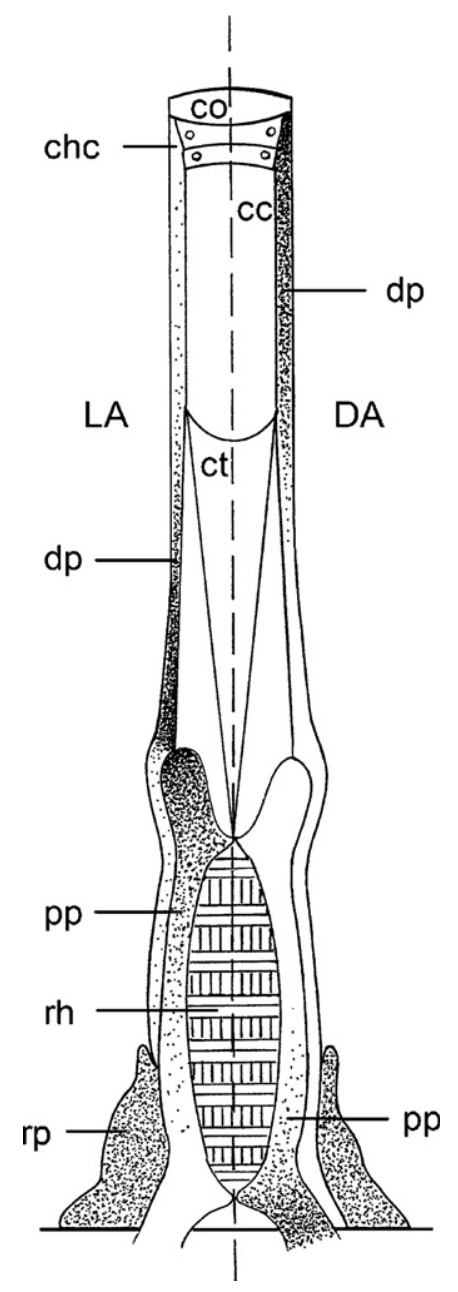

Fig. 3. Generalized representation of an Astacuran ommatidium. On the left: proximal and distal pigments in position for light adaptation (LA). On the right: proximal and distal pigments in position for dark adaptation (DA). Cornea (co), corneagenous cell (chc), crystalline cone (cc), distal pigment (dp), crystalline tract (ct), proximal pigment (pp), rhabdom (rh), reflecting pigment (rp).

receptors present at certain moments. Also, the duration of depolarisation shortens at circadian time 6 (CT 6) but becomes longer at CT 18 (Verde et al., 2007). This phase changing ability of PDH suggests that PDH acts as a circadian output factor just like PDF does in insects (Helfrich-Förster et al., 2000).

The electrical response to photic stimulation of the compound eye can also be recorded by means of an electroretinogram for which an electrode is placed on the surface of the eye. The magnitude of this response displays a clear circadian rhythm which has been extensively studied, particularly in crayfish (Aréchiga et al., 1993; Aréchiga and Rodriguez-Sosa, 1998). Exogenous PDH also showed to act as a non-photic synchroniser of this rhythm inducing phase advances or delays, depending on the time of application (Verde et al., 2007).

\subsubsection{Circadian entrainment}

Like all organisms on earth, crustacean species are exposed to daily changes of the environment caused by the daily rotation of our planet. Most animals and plants have a circadian (circa = around, dies = day) clock that enables them to anticipate these changes by adapting physiological processes and/or behaviour. Apart from rhythmic colour change and pigment dispersion (as described in the previous paragraphs), crustaceans also display circadian locomotor activity (a complete overview of crustacean circadian rhythms can be found in Table 1 of Strauss and Dircksen, 
2010). Although various studies have been carried out to analyse activity rhythms in crustaceans, it remains unclear how this circadian clock exactly functions. A central pacemaker has not yet unequivocally been identified and the question remains whether the crustacean clock exists of a single or of multiple dispersed pacemakers. Recently, Sullivan and co-workers did succeed in linking PDH to circadian entrainment in two Astacurans: P. clarkii and $C$. destructor (Sullivan et al., 2009).

In addition to the compound eyes, crayfish have extraretinal photoreceptive systems called brain photoreceptors (BPRs) and caudal photoreceptors (located in the sixth abdominal ganglion in the VNC) (Prosser, 1934; Wilkens and Larimer, 1972; Sandeman et al., 1990). These BPRs of $C$. destructor are excellent circadian photoreception cell candidates since they express cryptochrome, a photoprotein connecting directly to the circadian clock of plants, mice and insects and also histamine which is a neurotransmitter in several arthropod photoreceptor systems (Somers et al., 1998; Thresher et al., 1998; Stuart and Callaway, 1991; Stanewsky et al., 1998; Emery et al., 1998; Stuart et al., 2007). In order to examine the function of the BPRs in circadian entrainment, the compound eyes and caudal photoreceptors of $P$. clarkii and $C$. destructor were removed and the effects on photoentrainment of locomotor activity rhythms were investigated (Sullivan et al., 2009). Apparently, BPRs suffice to entrain locomotor rhythms to photic stimuli. Interestingly, the BPRs project to the BPN which is extensively innervated by PDHir neurons. As mentioned in Section 2.3, PDH levels in both $C$. destructor and P. clarkii vary simultaneously with the locomotor activity rhythms of each of these crayfish. The PDH-ir neurons in Cluster 6 of $C$. destructor might provide a direct link between light stimuli captured by the BPR and behavioural output (locomotion) as these interneurons connect to motor centers for locomotion in the suboesophageal and thoraric ganglia (Sullivan et al., 2009).

\section{Pigment dispersing factor in insects}

\subsection{The discovery and diversity of pigment dispersing factor peptides} in insects

Following the characterisation of PDH peptides in crustaceans, peptide extracts from insects showed to be able to induce pigment dispersion in the chromatophores of the crab $U$. pugilator and were named pigment dispersing factors (PDFs) (Dores and Herman, 1981; Mohrherr and Rao, 1985; Rao et al., 1987). The first non- crustacean pigment dispersing substance to be characterised, was the lubber grasshopper $R$. microptera PDF. The $R$. microptera peptide shows 78\% homology with $\beta$-PDH from $U$. pugilator (Rao et al., 1987). Insect PDF peptides are closely related to $\beta$-PDH as they consist of 18 amino acids, a N-terminal Asn, a C-terminal Ala (Nasionia vitripennis excluded) and at least $50 \%$ sequence similarity (Tables 1 and 2). Similarly to crustacean PDH, insect PDF originates from a larger precursor molecule consisting of a signal peptide, a PDF-associated peptide and the mature PDF flanked by mono and/ or dibasic cleavage sites.

Some beetles, e.g. Tribolium castaneum, seem to lack PDF ( $\mathrm{Li}$ et al., 2008). A tBLASTn with the D. melanogaster PDF receptor and C. elegans PDF receptors as query sequences does however reveal a possible PDF receptor in T. castaneum (XP_971738.1).

\subsection{Pigment dispersing factor localisation}

As a result of growing interest in the PDF peptide, a vast variety of insects adds up to the list of localisation studies. Originally, these experiments were performed using antibodies raised against $\beta$ PDH; this approach is still valuable as a first indication of PDF localisation in species with yet unknown PDF sequences. Such results should nevertheless be handled with caution, as they may slightly differ from true PDF patterns due to cross-reaction.

While some common conclusions can often be made considering the localisation of PDF in the central nervous system (Table 3), species specific details can differ substantially. In the following description, we would like to point out some recurring themes, without ignoring the diversity observed over the different species. Both brain and abdominal PDF neurons have been identified, supporting a true neurohormonal role for this peptide.

\subsubsection{PDF neurons in the insect brain}

3.2.1.1. Three distinct clusters in hemimetabolan representatives. The hemimetabolan species so far studied all seem to have three distinct PDH or PDF immunoreactive (PDH-ir or PDF-ir) clusters in the optic lobe as hallmark. Multiple representatives of Phasmida, Dictyoptera, Dermaptera, Othoptera and Hemipteroid origin have been probed for putative PDF neurons in numerous experiments, but many await neuroanatomical identification in order to validate a hypothesis for most members of the hemimetabolan lineage.

Table 2

Sequence alignment of insect PDF peptides. Identical amino acids are highlighted in black, conserved amino acids in dark gray. $\mathrm{X}=\mathrm{I}$ or $\mathrm{L}$.

\begin{tabular}{|c|c|c|}
\hline Species & Peptide sequence & Reference \\
\hline \multicolumn{3}{|l|}{ Insect PDF } \\
\hline Drosophila virilis* & NSELINSLLSLPKNMNDAamide & n.d. \\
\hline Phormia regina* & NSELINSLLSLPKNMNDAamide & (Matsushima et al., 2004) \\
\hline Drosophila melanogaster & NSELINSLLSLPKNMNDAamide & (Park and Hall, 1998) \\
\hline Apis mellifera & NSELINSLLGLPKNMNNAamide & (Boerjan et al., 2010) \\
\hline Nasonia vitripennis* & NSELINSLLSLPKNMNNTamide & n.d. \\
\hline Anopheles gambiae* & NSELINSLLSLPKTMNDAamide & n.d. \\
\hline Musca domestica* & NSELINSLLSLPKSMNDAamide & n.d. \\
\hline Bombyx mori* & NADLINSLLALPKDMNDAami de & (Roller et al., 2008) \\
\hline Acheta domesticus & NSEIINSLLGLPKVLNDAamide & (Rao and Riehm, 1989) \\
\hline Gryllus bimaculatus* & NSEIINSLLGLPKVLNDAamide & (Chuman et al., 2002; Singaravel et al., 2003) \\
\hline Meimuna opalifera* & NSEIINSLLGLPKVLNDAamide & (Sato et al., 2002) \\
\hline Romalea microptera & NSEIINSLLGLPKLLNDAamide & (Rao et al., 1987) \\
\hline Schistocerca gregaria* & NSEIINSLLGLPKLLNDAamide & Personal communication J. Tobback \\
\hline Leucophaea maderae & NSEXINSLLGLPKVLNDAamide & (Hamasaka et al., 2005) \\
\hline Periplaneta americana & NSELINSLLGLPKVLNDAamide & (Mohrherr et al., 1991) \\
\hline Carausius morosus & NSELINSLLALPKVLNDAamide & (Mohrherr et al., 1994) \\
\hline Blatella germanica* & NSELINSLLGLPKVINDAamide & n.d. \\
\hline
\end{tabular}

*Amino acid sequence derived from cDNA precursor sequence (ClustalW2 and BOXSHADE 3.21). 
Table 3

Overview of anatomical terms and orthologous structures. (A) Different terminology for insect structures. (B) Orthologous PDH/PDF-positive cells in arthropods.

\begin{tabular}{|c|c|c|}
\hline \multicolumn{3}{|l|}{ (A) Terminology } \\
\hline \multirow{3}{*}{\multicolumn{3}{|c|}{$\begin{array}{l}\text { Distal posteriodorsal }=(\text { dorsal }) \text { PDFLa } \\
\text { Distal posterioventral = }(\text { ventral }) \text { PDFLa } \\
\text { Proximal frontoventral = PDFMe }\end{array}$}} \\
\hline & & \\
\hline & & \\
\hline \multicolumn{3}{|c|}{ (B) Orthologous structures in arthropods } \\
\hline $\begin{array}{l}\text { L. maderae } \\
\text { (Hemimetabola) }\end{array}$ & $\begin{array}{l}\text { D. melanogaster } \\
\text { (Holometabola) }\end{array}$ & $\begin{array}{l}\text { H. americanus } \\
\text { (Crustacea) }\end{array}$ \\
\hline \multicolumn{3}{|l|}{ Anterior PDFMe } \\
\hline-4 large & 4 l-LNvs & Group C neurons \\
\hline-4 medium & $4 \mathrm{~s}-\mathrm{LNvs}$ & \\
\hline-4 small & - & \\
\hline Posterior PDFMe & - & \\
\hline PDFLa (ventral \& dorsal) & - & $\begin{array}{l}\text { Cells in proximal part } \\
\text { of lamina ganglionaris }\end{array}$ \\
\hline
\end{tabular}

The very first localisation experiment in insects was performed in the grasshopper $R$. microptera, where PDH-ir was detected in three cell groups in the optic lobes and in widely distributed arborisations in the supraoesophageal ganglion (Zahnow et al., 1987). Comparative studies further confirmed the appearance of these three clusters in other species (Nässel et al., 1991; Homberg et al., 1991b; Sato et al., 2002; Sehadová et al., 2003; Honda et al., 2006; Wen and Lee, 2008). Two cell groups are localised at either the posterior dorsal or posterior ventral edge of the lamina and are therefore together known as the PDFLa cells or separately as the distal posteriodorsal and posterioventral clusters. The third group can be observed at the anterior edge of the medulla and is referred to as the PDFMe cells or the proximal frontoventral cluster (Fig. 4 and Table 3) (Nässel et al., 1991; Homberg et al., 1991b; Sehadová et al., 2003).

Although the number of observed PDH-ir PDFLa cells varies between species, they are of equal dimensions and invariably project into the lamina, accessory medulla (aMe) and distal medulla. The network of fibers that spreads over the medulla ends in the first optic chiasm or in the lamina (Fig. 4) (Homberg et al., 1991b; Sehadová et al., 2003).

While generally regarded homologous group of neurons over the investigated species, the PDFMe neurons show more variation regarding the size of the somata and the individual innervation patterns in the midbrain. Noteworthy are outgrowths in the lateral protocerebrum and in two areas close to the mushroom bodies (Homberg et al., 1991b), as well as a connection between the two bilaterally located PDH-like systems (Sehadová et al., 2003) (Fig. 4).

The presence of additional PDH-ir neurons in proto-, deuteroand tritocerebrum as well as suboesophageal ganglion, frontal ganglion, recurrent nerve and corpora cardiaca differs among species. Detailed functional consequences are not known (Sehadová et al., 2003; Abdelsalam et al., 2008). In some species PDH-ir in the posterior optic tubercles suggests an indirect connection between PDFMe neurons and the central complex (Homberg et al., 1991b).

We would like to give a slightly more detailed description of the optic lobe PDH-ir architecture in the cockroach Leucophaea maderae, since it is by far the best studied hemimetabolan model with regard to PDF localisation. Its PDF expression pattern is often compared to the PDF-system of the holometabolan fruit fly D. melanogaster (Table 3 ). In the optic lobe of $L$. maderae, four groups of PDH-ir neurons can be identified: anterior and posterior PDFMe neurons, and ventral and dorsal PDFLa neurons. Constructing a 3D-model of the cockroach aMe and its PDH-ir innervation, three subgroups of the twelve anterior PDFMe neurons could be identified: four with large, four with medium and four with small somata. The large anterior PDFMe cells might synaptically connect to serotonergic neurons and are proposed as homologues of the D. melanogaster l-LNvs (Fig. 4), whereas the medium PDFMe probably interact with different

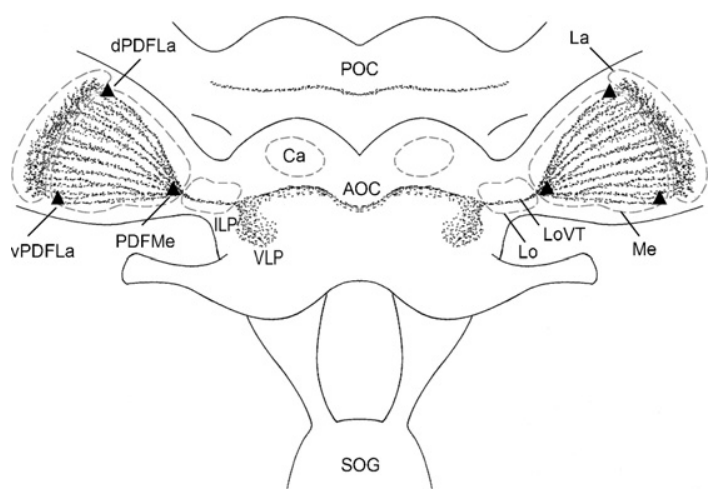

Fig. 4. Schematic overview of recurring PDF-regions in the hemimetabolan brain. Three clusters of PDF-producing cells (dPDFLa, dorsal PDFLamina cells; vPDFLa, ventral PDFLamina cells; PDFMe, PDFMedulla cells) provide ramifications in lamina (La), medulla (Me) and lobula (Lo; LoVT, lobula valley tract) of the optic lobe and the lateral regions of the protocerebrum (ILP, inferior lateral protocerebrum; VLP, ventral lateral protocerebrum), and connect both hemispheres (AOC, anterior optic commissure; POC, posterior optic commissure; Ca, calyx of the mushroom body; SOG, suboesophageal ganglion; triangles represent cell clusters and not individual neurons).

partners and are related to the D. melanogaster s-LNvs. Only the small PDFMe have projections that are limited to the ipsilateral optic lobe, and do not have D. melanogaster LNv counterparts. Contralateral communication through large and medium PDFMe neurons is thought to serve in a circadian coupling pathway (Reischig and Stengl, 2003b; Reischig et al., 2004).

Although there are some general aspects, not all representatives of even the same order invariably fulfil them. An example can be found in a study of PDF immunoreactivity in a number of termite species. Despite some differences, there are general aspects for most termite species: there is but a limited number of PDF-ir neurons in the PDFMe cluster, but the tritocerebrum and frontal ganglion are greatly innervated and there are PDF-ir perikarya observed in the suboesophageal ganglion (Závodská et al., 2008). Note that the presence of the PDFMe cluster only, is reminiscent of a holometabolan PDF-architecture (see Section 3.2.1.2). The PDF-cells of the suboesophageal ganglion supply, amongst other targets, fibers to the corpora cardiaca. This innervation pattern is rare in non-termite insects, indicating an order-specific characteristic of PDF-staining. It should be noted that absence of PDH-ir neurons in the optic lobe is extremely rare, yet it has been observed in two termite species, Reticulitermes flavipes and Macrotermes carbonarius, indicating species-specific deviations of the general pattern (Závodská et al., 2009). It would certainly be interesting to further investigate the consequences of this absence in termites.

Some studies report on subcellular localisation of PDF. In G. bimaculatus, PDF is not only detected in the cytoplasm of medulla and lamina neuropils, but can also be observed in the nucleus of at least some of the PDFLa cells. This is supported by the precursor sequence, which differs slightly from the common PDF sequences, in that it does not have a clear signal sequence, but a nuclear localisation sequence instead (Chuman et al., 2002). It is possible that in this species, PDF performs an additional role in the nucleus. Such nuclear localisation was on the other hand not observed in the last summer cicada Meimura opalifera (Sato et al., 2002), indicating species-specific differences.

Another molecular property that is associated with localisation is isoform formation. Although the existence of PDH isoforms was well known for crustaceans, it was not until 2006 that this suggestion was made for insects. Honda and colleagues used a variety of antibodies raised against $G$. bimaculatus PDF, each one recognizing a different epitope. Immunostaining then revealed that the 'standard' PDF is 
present in the aMe, PDFMe cells, the inner PDFLa cells and their axons; while an isoform was detected in the PDFLa outer cells and a varicose arborisation in the lamina. As the outer PDFLa cells do not provide $p d f$ mRNA, this peptide may be a product of another gene. It is however possible that there is no different gene, but that some antibodies do not recognize a structural change of the peptide (Honda et al., 2006). The information is nevertheless interesting, as isoforms create many new physiological possibilities that are yet to be investigated for insects.

Based on these localisation studies, hypotheses on PDF functions in insects have been made, such as control of the endocrine route (Wen and Lee, 2008; Vafopoulou et al., 2010) and functions in the circadian clock mechanism (see Section 3.4).

3.2.1.2. PDFMe neurons in holometabolan representatives. All Endopterygota studied so far display PDH/PDF-ir in the PDFMe cluster. PDFLa neurons seem to be absent in these insects. With the fruit fly as leading animal model for decades, PDF neurolocalisation data are yet available in great detail. Additional studies conducted in other holometabolan species broaden the view with some deviations from the general PDF pattern.

Three distinct clusters of PDH-ir neurons were originally identified in the brain of the fruit fly $D$. melanogaster, of which only one remains visible in adult flies (Helfrich-Förster, 1997): the D. melanogaster PDFMe neurons are observed throughout development into the adult stage. These neurons are also named the ventrolateral neurons, and are divided into two distinct groups, according to the size of their somata: there are five small (s-LNvs) and four large ventrolateral neurons (1-LNvs) (Fig. 5). Only four sLNvs are PDH-ir. They all project into the superior protocerebrum and have dendrites in the larval optic lobe neuropil, and its adult counterpart, the aMe. The l-LNvs differentiate during metamorphosis, during which connections to the aMe and medulla become visible. The l-LNvs additionally connect both brain hemispheres by projecting contralaterally via the posterior optic tract (HelfrichFörster, 1997) (Fig. 5). Some l-LNv neurons were first thought to send collaterals into the dorsal brain, but this was not observed in later studies (Park and Griffith, 2006; Helfrich-Förster et al., 2007). This means that the l-LNvs are the only clock neurons not projecting into the dorsal brain (Helfrich-Förster et al., 2007). A recent study reporting on mRNA populations enriched in the LNv neurons as compared to the entire head, supports the observation that PDF presence in adult brains is restricted to these neurons solely (Kula-Eversole et al., 2010). Similarly, two groups of at least four lateral neurons in each optic lobe of the housefly Musca domestica express $p d f$. They appear to correspond to the small and large LNvs of $D$. melanogaster (Matsushima et al., 2004). It should be noted that the presence of PDF in the s-LNvs of the housefly is subject of debate (Bahn et al., 2009). Eight PDFMe cells are also present in each hemisphere of the blowfly Protophormia terraenovae. Four of them have large somata, the other four somata are of a smaller diameter (Nässel et al., 1991) (Fig. 5). In blowfly larvae, however, only seven PDFMe were observed by Hamanaka et al. (2009). Two large axons originating from two of the large somata represent the connection with the lamina of the optic lobes. Other projections are observed in three medulla layers, in a region adjacent to the mushroom body calyx, in the posterior optic tract and medial above the oesophageal foramen (Nässel et al., 1991) (Fig. 5). For fruit flies, it has been proposed that the l-LNv receive ipsilateral extraretinal photic input from the Hofbauer-Büchner eyelet (Helfrich-Förster et al., 2007). Similarly, direct connections of such an eyelet with PDF-ir neurons have been described for the blowfly (Yasuyama et al., 2006). The bumblebee and honeybee PDFMe neurons provide limited innervation of lamina, medulla and the proximal region of the posterior lobula. The protocerebral neuropils are delineated by PDH-ir commissural fibers (Bloch et al., 2003; Weiss et al., 2009).

For the fruit fly, an additional cluster of two to four PDH-ir neurons was initially detected close to the calyces of the mushroom bodies in adults, and therefore named PDFCa neurons. They were thought to send axons via the median bundle to the tritocerebrum (Helfrich-Förster and Homberg, 1993; HelfrichFörster, 1997). Unlike for the LNv neurons, however, these results could not be confirmed by anti-DrmPDF staining or in situ hybridisation (Park and Hall, 1998; Renn et al., 1999; Park et al., 2000). This cluster was therefore considered to result from crossreaction (Renn et al., 1999; Park et al., 2000).

The second cluster of fruit fly PDH-ir neurons in the tritocerebrum displays immunoreactivity during a short period in development: from about halfway metamorphosis until four days after eclosion. The somata are located ventrally from the oesophageal foramen and their fibers run dorsally in the median bundle to the pars intercerebralis and lateralis (Helfrich-Förster, 1997; Renn et al., 1999; Park et al., 2000). The decrease of the PDF-

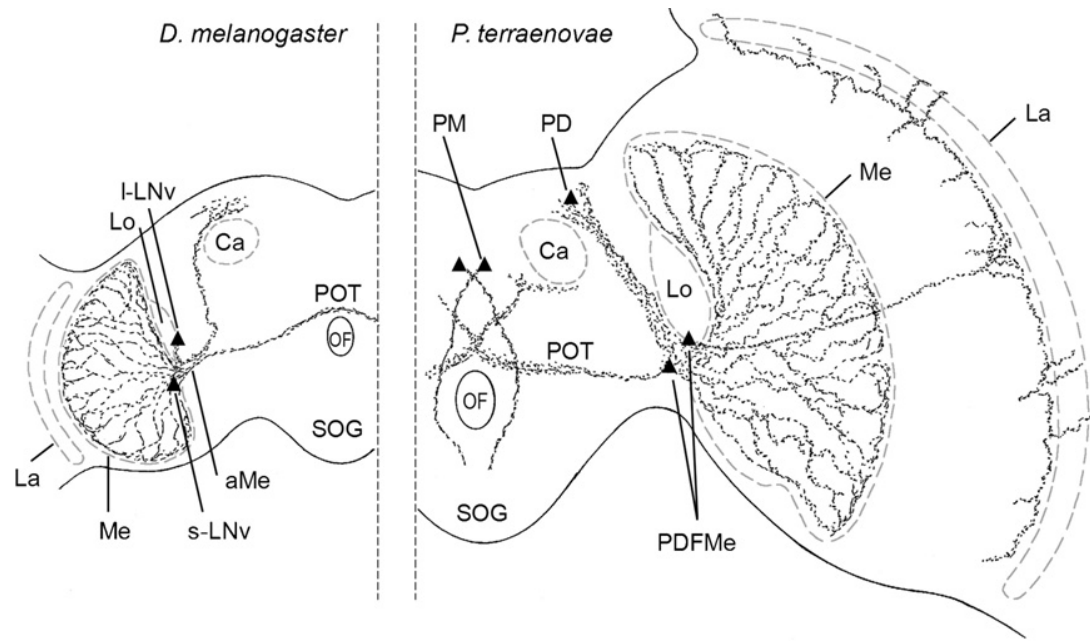

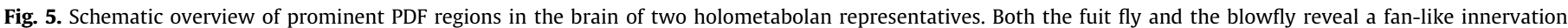

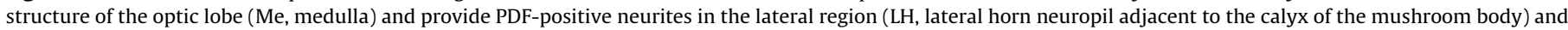

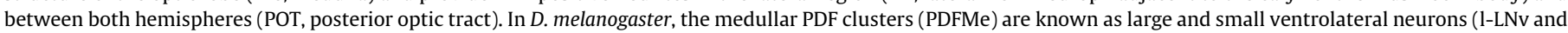

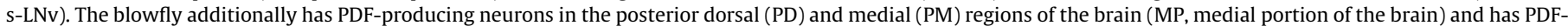

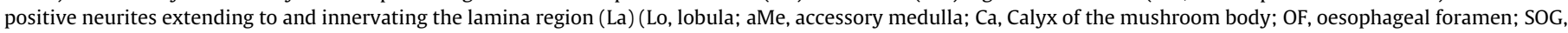
suboesophageal ganglion; triangles represent cell clusters and not individual neurons). 
signal after eclosion most likely reflects a complete retraction of the neurons themselves (Fernández et al., 2008). In general, more PDF-ir neurons are found in D. melanogaster larvae compared to adults and staining decreases with age in adult flies, while the pattern remains the same (Helfrich-Förster et al., 2000).

In the blowfly $P$. terraenovae, apart from PDFMe staining, an additional pair of $\mathrm{PDH}$-ir cell bodies is located close to the posterior midline (Nässel et al., 1991); this pair is also observed in larval flies and has axons that cross the midline and project ventrally along the foramen of the oesophagus, terminating in the dorsal region of the suboesophageal ganglion (Hamanaka et al., 2009) (Fig. 5). Another eight cell bodies could be detected in the lateral neurosecretory cell group of the superior protocerebrum (Nässel et al., 1993) (Fig. 5). Projections are observed in the median bundle, and some even seem to run posteriorly into the cervical connective, which is the spinal cord equivalent descending from the fly's brain. Three pairs project to the corpora cardiaca and retrocerebral complex (Nässel et al., 1993). In larvae, a pair of ascending fibers, possibly derived from cells in the thoracic-abdominal ganglion, terminates close to the optic neuropil. PDF-ir fibers, likely derived from pars lateralis cells, were furthermore detected in the wall of the aorta, but not in the ring gland. PDF could be released from the aorta in the hemolymph (Hamanaka et al., 2009).

The limited number and considerable dimensions of the moth Manduca sexta's neurosecretory cells allowed an early identification of PDH-ir neurons. A dorsomedial cluster of brain neurosecretory cells with prominent arborisations in the tritocerebrum was found to express a PDH-like substance. Interestingly, in this species no PDH-ir cells were observed in the aMe (Homberg et al., 1987, 1991a; Wise et al., 2002).

On the cellular level, Miśkiewicz et al. clarified the longpresumed presence of PDF in the dense core vesicles, studying both the fruit fly and the housefly, and verified that the peptide is released in a non-synaptic, paracrine way (Miśkiewicz et al., 2004). They could also show that PDF is the only peptide present in the housefly's PDH-ir varicosities of the medulla (Miśkiewicz et al., 2008). This sheds a new light on PDF localisation studies in other insects that might need to be reinvestigated at subcellular level. Colocalisation with RFamide-like peptides was observed in $M$. sexta by means of immunostaining with gastrin/cholecystokinin antibodies (Homberg et al., 1987, 1991a) and it seems that PDF colocalises with RFamide-like peptides and corazonin at least in some neurons in the brain of the blowfly (as observed with antibodies against CCK-8, corazonin and FMRFamide) (Hamanaka et al., 2007, 2009). Many studies have suggested that FMRFamide, a neuropeptide that is - like PDF - thought to regulate circadian clock output, is colocalised with PDF in some neurons (Homberg et al., 1991a; Nässel et al., 1993; Meinertzhagen and Pyza, 1999; Pyza and Meinertzhagen, 2003; Settembrini and Villar, 2005). More recent findings contradict the presence of FMRFamide in PDF-neurons, at least for the fruit fly and the housefly. As these experiments were conducted in great detail, it is assumable that FMRF-neurons and PDF-neurons comprise separate, though closly associated neuron sets (Matsushima et al., 2007).

Based on localisation patterns, some indications concerning structure-function relations can be derived. For example, the L1 and L2 first order interneurons are the most important target interneurons of the photoreceptor terminals in the housefly $M$. domestica. While PDH-ir cells influence L1 and L2, direct synaptic connections between both have not been described. It has therefore been proposed that lamina glial cells might be involved in transmitting the signal (Meinertzhagen and Pyza, 1996), or that the peptide diffuses to its site of action (Meinertzhagen and Pyza, 1999). In D. melanogaster, medulla neuropil glial cells are similarly thought to be involved in certain functions of the PDF-system and are in close contact with the terminals of the PDF-positive l-LNvs
(Górska-Andrzejak et al., 2009). Since there is also evidence for serotonin to influence the housefly L1/L2 and some serotoninpositive processes run along PDH-positive ones, these neurons could work together in the circadian regulation (Meinertzhagen and Pyza, 1996). Interestingly, blowfly serotonin immunoreactive neurons equally show the same general expression pattern as PDH-ir neurons, though comprising a distinct group of cells. This observation is also valid for the cockroach $L$. maderae, suggesting that both molecules might be functionally coupled, with common follower neurons (Nässel et al., 1991).

Other neurotransmitters influencing the housefly L1 and L2 cells are histamine, glutamate and GABA. Only the latter is proposed as another candidate for circadian regulation, a major function of PDF (Meinertzhagen and Pyza, 1999).

\subsubsection{Abdominal PDF neurons in insects}

PDF is a neuropeptide for which there is often information available both on local functions in the brain as well as on probable hormonal roles within the same animal. A more detailed study on the central action of PDF by electrophysiologically investigating the abdominal PDF neurons (PDFAb) of Locusta migratoria revealed two types of PDF-ir neurons in the abdominal ganglia. Lateral neurons project to heart nerves and perisympathetic organs, which are the release sites for neurosecretory products of the VNC. Therefore, these PDFAb neurons are ideally situated to support a hormonal role for the neuropeptide. The less complex median neurons innervate the hindgut and posterior midgut. PDF, however, does not influence hindgut contractility, but seems to be released into the hemolymph, again indicating an additional hormonal function for this neuropeptide (Persson et al., 2001). In general, considerable variation exists between the insect PDFAb neurons. For D. melanogaster, only neurons similar to the median neurons have been observed while closely related blowflies may express the peptide in more cells. Moths have some PDFAb neurons, but cockroaches and crickets seem to have none (Homberg et al., 1991a; Persson et al., 2001; Wise et al., 2002; Wen and Lee, 2008).

The third cluster of PDH-ir neurons of $D$. melanogaster, located in the eight abdominal neuromere of the ventral ganglion, comprises the PDFAb neurons. They undergo severe reorganisations throughout development, but PDF-production is also observed after these neuronal changes. Axons from the PDFAb neurons innervate the most caudal part of the midgut and the hindgut. Since they are closely associated with the circular muscles of the posterior midgut, they might provide direct innervation. Abundant expression of the PDF receptor (PDFR) in the crop furthermore suggests that PDF could be released into the hemolymph (Veenstra et al., 2008).

In the thoracic-abdominal ganglion of the blowfly, all of the 36 neurons label weakly with $\beta$-PDH antiserum, except for three pairs of ventral abdominal neurons that show strong PDH-ir. These three pairs are also observed in the fruit fly. The PDFAb cells innervate all abdominal neuromeres and send projections to the hindgut (Nässel et al., 1993).

\subsection{Time-related expression}

Because of the tight association between PDF and the biological day-night rhythm, several researchers have looked into the possibility of daily PDF or PDF-associated expression rhythms. Obviously, there are more biological clock-related changes than those described below. Here, we will focus on PDF.

For the blowfly $P$. terraenovae and the cockroach $L$. maderae, no differences of PDH-ir could be observed over the course of the day (Nässel et al., 1991; Hamasaka et al., 2005). One should keep in mind that more subtle differences below the detection level cannot be excluded. Similarly, the hemolymph PDF levels of $L$. migratoria 
showed no significant difference between morning and evening. This should be interpreted separately from the information concerning the brain, as abdominal PDF may function as a clock-independent circulating neurohormone, in addition to its local function in the CNS (Persson et al., 2001). In contrast to these constant PDF levels, both cricket nymphs and adults show daily changes in PDF content of the optic and cerebral lobes (Abdelsalam et al., 2008). Cycling PDF levels have also been observed in Rhodnius prolixus (Vafopoulou et al., 2010).

Both the housefly $M$. domestica and the fruit fly $D$. melanogaster have been studied into more detail concerning PDF-associated rhythms. The housefly exhibits two circadian rhythms in its visual system that are dependent on PDF input (Pyza and Meinertzhagen, 1996; Balys and Pyza, 2001). Firstly, a fluctuation in synaps number is observed between photoreceptor terminals and their target interneurons L1 and L2, and in feedback synapses formed by L2. Secondly, the axons of both interneurons seem to change in size during the day, being at their largest during the day, and shrinking by night (Meinertzhagen and Pyza, 1996, 1999). Although these changes are circadian, they are also directly influenced by light. PDF itself is in the housefly cyclically released from varicosities of $\mathrm{PDH}-\mathrm{ir}$ terminals in a paracrine, nonsynaptical fashion (Miśkiewicz et al., 2008). For the fruit fly, Northern blotting pdf mRNA revealed a slight, though never significant cycling over the course of a day and was therefore considered stable (Park and Hall, 1998). Interestingly, although the RNA is produced in a constant fashion (Park and Hall, 1998; Park et al., 2000), the peptide levels at the axon terminals oscillate with a daily pattern: they are most abundant in the early morning and reach their lowest levels about $1 \mathrm{~h}$ after lights off (Park et al., 2000). Cycling peptide levels were observed in the s-LNvs, but not in the l-LNvs or their processes. It is thought that this reflects a daily rhythm of peptide processing, transport or release (Park et al., 2000). Thus not only pdf RNA and peptide localisation, but also the temporal expression within one neuron is different (Helfrich-Förster et al., 2000). In addition to changes in peptide levels, the dorsal axon terminals of the s-LNvs undergo daily morphological changes, being more complex during the day than during the night. The rhythm persists under constant darkness (DD), indicating the true circadian nature. This clock-controlled neuron plasticity could participate in the regulation of downstream information transmission (Fernández et al., 2008). As in the housefly, daily changes in L1 and L2 size and shape are similarly observed for D. melanogaster (Meinertzhagen and Pyza, 1999). In contrast to the observations for the brain, PDF levels seemingly remain constant in the abdominal cells of the ventral ganglion (Blau and Young, 1999).

Whereas it is clear that PDF itself is crucial for normal circadian behaviour, there are studies that argue that PDF cycling per se might not be as important for daily rhythms as assumed, since adult flies without PDF cycling remained rhythmic in DD (Kula et al., 2006). Also, this could explain why constant amounts of membrane-tethered PDF can produce (though abnormal) rhythmic behaviour in a pdf deletion mutant (Choi et al., 2009; Taghert, 2009). So far, there is no single explanation for these phenomena.

\subsection{Function of the PDF system}

\subsubsection{The visual system and the biological clock}

It is impossible to discuss PDF function and regulation without a basic understanding of the molecular nature of the circadian clock. In an extremely simplified, but for this purpose sufficient view, we can state that most organisms endogenously generate $24 \mathrm{~h}$ rhythms based on negative feedback loops of gene transcription activation and inhibition. For the fruit fly and many other insects, heterodimers of the transcription factors
CLOCK (CLK) and CYCLE (CYC) activate the transcription of period (per) and timeless (tim) genes, whose protein products impair the CLK/CYC binding to the DNA, thus negatively regulating their own transcription. Apart from many posttranscriptional regulations, a second loop including the genes $p d p-1$ (PAR domain protein 1) and vrille acts to stabilize this oscillator. Clock neurons are typically the PER-producing neurons, which do not invariably colocalise with PDH-ir neurons (Závodská et al., 2003).

Historically, the search for PDF function in insects originates in the tight association of the peptide with the visual system. Because the involvement of PDF in the insect eye pigment migration has not been reported and epithelial chromatophores are absent in these animals, a different function for the neuropeptide must be present (Chen et al., 1992; Rao and Riehm, 1993; Pyza and Meinertzhagen, 1997 and references therein).

PDF-positive neurons transfer and modulate rhythmic and photic signals, and connect both accessory medullae (aMe) (Nässel et al., 1993; Tomioka and Abdelsalam, 2004; Yasuyama et al., 2006; Helfrich-Förster et al., 2007). Whereas for most studied species PDF is a crucial but not the sole signalling molecule required for normal circadian locomotor activity (Taghert et al., 2001), this may yet be the case for the nocturnal German cockroach (Lee et al., 2009).

Much of the early work on circadian rhythms has been performed on cockroaches, where it was shown that cutting the optic stalks causes degeneration of PDH-ir terminals, accompanied by the loss of circadian locomotor rhythms. Regeneration of these terminals is furthermore associated with a reappearing circadian locomotor rhythm (Stengl and Homberg, 1994). Similarly, changes in PDFMe neuron arborisations accompany splitting in the locomotor rhythm in D. melanogaster mutants, meaning that the rhythm decomposes into its components, thus connecting the PDFMe neurons to the circadian clock (Helfrich-Förster and Homberg, 1993). It should be noted that the PDFMe neurons are not the clock neurons in all insects, for example not in the cricket $G$. bimaculatus (Okamoto et al., 2001).

The first direct physiological evidence for a circadian PDH function in insects was also achieved for the cockroach. After injecting synthetic PDH in the accessory medulla region of $L$. maderae, Petri and Stengl (1997) were able to elicit an amountand phase-dependent resetting of the circadian locomotor rhythm. PDH in insects could therefore, either as a nonphotic input signal or as an integral part of the circadian pacemaker, couple the bilaterally paired circadian pacemakers. Additionally, they showed that the phase delay amplitude resulting from PDH injections was similar tot that caused by serotonin (Petri and Stengl, 1997). Later, actions of PDF, FMRFamide and serotonergic neurons have been identified in the tight coupling between both brain hemispheres (reviewed by Helfrich-Förster, 2004). Reischig and Stengl were furthermore able to restore circadian locomotor activity by ectopically transplanting the adult accessory medulla into optic lobeless cockroaches. Restoring the rhythm was accompanied by formation of PDH-ir neurons from the graft to the protocerebral targets. These experiments proved that at least the large- and medium-sized PDH-ir neurons are pacemaker neurons in the accessory medulla of $L$. maderae (Reischig and Stengl, 2003a).

In addition to circadian locomotor activity regulation, a PDF-dependent mechanism of the l-LNvs is part of a lightactivated arousal circuit, modulating behavioural arousal and sleep in the fly brain (Sheeba et al., 2008a). The l-LNv arousal circuit probably uses octopamine, the insect counterpart of vertebrate noradrenaline, as important signalling molecule (Kula-Eversole et al., 2010). Relations to or interactions with the PDF-system remain to be revealed. 


\subsubsection{PDF is a network-coordinator}

With the generation of a null mutant for the pdf gene of the fruit fly, Renn et al. (1999) were able to functionally study the influence of this neuropeptide in detail and prove it to be a true clock output gene. Both $p d f$ mutant flies and animals with ablated $p d f$ neurons showed similar behavioural phenotypes when scoring the activity levels, indicating that $p d f$ is the principal signalling molecule in these neurons. The mutant flies remained rhythmic in LD conditions, but lost rhythmicity after two days in DD; thus reflecting the gradual loss of pacemaker synchronisation by PDF (Renn et al., 1999). It is noteworthy that Drosophila virilis activity rhythms interestingly resemble those of $D$. melanogaster $p d f$ null mutants. Additionally, D. virilis do not stain for PDF in the s-LNvs (Bahn et al., 2009), the major neurons to mediate PDF output regulation of locomotor behaviour (Park and Hall, 1998; Park et al., 2000). This led the authors to the promising hypothesis that different regulation of $p d f$ transcription might be responsible for species-specific activity patterns (Bahn et al., 2009). Further experiments will need to clarify this possibility.

A small fraction of mutant $D$. melanogaster that remained rhythmic during DD indicates that there must be additional pacemaker neurons involved in regulating circadian behaviour (Renn et al., 1999). It has been proposed that the initial weak rhythmicity in the pdf null DD-flies is due to dampening PER oscillations in the DN1 neurons. Studying flies that lack the DN1 on the contrary revealed that their oscillations are dependent on PDF expression in the LNvs (Klarsfeld et al., 2004). The need of PDF for robust free-running rhythms is supported by a study of Peng et al., where it was shown that the LNvs alone are not sufficient to maintain circadian locomotor activity, but that the neuropeptide is additionally required for coordination of the circadian network (Peng et al., 2003). If the individual clock neurons are not synchronised, the overall result will be arrhythmia. The fact that both $p d f$ null and ablated flies show similar phenotypes, underscores that PDF secretion is probably the most important function of the LNvs (Renn et al., 1999). It should nevertheless be noted that $p d f$ expressing s-LNv neurons coexpress short neuropeptide $F$, which is diversely expressed in the fruit fly's brain (Johard et al., 2009; KulaEversole et al., 2010). Further study revealed that PDF is not required to maintain circadian protein oscillations, but that it is crucial to coordinate the phase and amplitude of circadian protein oscillations under constant conditions (DD) (Lin et al., 2004). There seems to be a hierarchical communication from the LNvs to the LNds, with PDF acting to delay phases in order to maintain synchrony. This action can probably molecularly be translated to the regulation of PERentrance into the nucleus via kinases such as DOUBLETIME, SHAGGY and CALMODULIN KINASE II. Not only does PDF entrain the LNd neurons, it also feeds back to help synchronise the s-LNvs. If then all pacemaker cells generate in-phase, robust circadian PER-cycling, the overall generated rhythm will surpass a threshold that is needed for phenotypic day-night rhythmicity (Lin et al., 2004).

The network-coordinating action of PDF on the aMe neurons is related to GABAergic signalling in the cockroach. The effects of GABA and PDF on excised aMe revealed detailed organisation and function of the cockroach aMe. Ultradian firing aMe neurons are organised into phase-locked assemblies via GABAergic interneurons. Different assemblies have a stable phase difference. They can be synchronised to the same phase and period by PDF, thus generating resonance and producing a sufficient signal to cause postsynaptic cell firing. PDF acts inhibitory on GABAergic and other inhibitory interneurons, thereby activating the output to locomotor centres (Schneider and Stengl, 2005).

Recent findings show that PDF feedback on clock neurons influences their period in a dual way: it will lengthen the period of some clock neurons closely associated with the aMe, while that of others in the dorsal brain shortens with increasing PDF input. Using
D. melanogaster mutants that show gradually increasing 1-LNv projections into the dorsal brain instead of the aMe, it could be shown that PDF causes the observed period alterations, because in $p d f$ null background these changes disappeared. The neuropeptide therefore seems to act differently at different sites of the brain (Wülbeck et al., 2008). Further evidence for this hypothesis was gathered when studying the effects of PDF on specific subgroups of clock neurons. For some clock neurons, PDF exerts a period lengthening and synchronisation function. In others, it is not needed for these functions, but has a strong period influence that can either be lengthening, shortening or both depending on PDF concentration. In the latter case, neuropeptide F may counteract PDF effects. These neurons with multicomponent rhythms also appear to depend on environmental signals. This is interesting because it suggests a critical role for PDF in the coordination of the entire clock network, where regulation of phases of different neuron groups represents a natural function in seasonal adaptation (Yoshii et al., 2009). Activation of the PDF receptor similarly accelerates certain clock neurons, while decelerating others (Choi et al., 2009).

Another argument for differential regulation with regard to PDF function can be found in flies with altered shibire, a homologue of dynamin. On one hand, these animals display altered behavioural period, but only when PDF is also present. This indicates a PDFdependent influence on clock output pathways. On the other hand, SHIBIRE can alter the s-LNv molecular clock, even in a pdf null background. Therefore, this effect is a consequence of a novel, PDFindependent pathway (Kilman et al., 2009).

\subsubsection{Possible role in circadian rhythm plasticity}

Social insects show plasticity of circadian rhythms among colony members, related to their specific tasks. Bombus terrestris workers are divided in large and small individuals related to their colony activities. Large bumblebees have daytime activities outside the colony and show strong circadian rhythmicity, whereas smaller bees usually stay in the nest to tend brood arrhythmically around the clock. In general, large B. terrestris have one additional PDH-ir neuron per brain hemisphere compared to smaller bees. The origin of this difference is currently not known, but may be due to developmental processes in pre-adult stages. The change in PDH-ir neuron number may affect the observed rhythm differences between large and small bumblebees (Weiss et al., 2009).

\subsubsection{PDF action under temperature cycles}

Although circadian clock function is mostly studied with regard to changing light conditions, temperature cycles can drive circadian rhythmicity under LL as well as DD conditions; this is driven by other neurons than pdf expressing cells (Yoshii et al., 2005; Glaser and Stanewsky, 2005, 2007; Sehadová et al., 2009 and references therein). In fact, a combination of differences in light intensity and temperature may result in altered behaviour dictated by the same cells. For example, DN1 neurons can promote both morning and evening activity, depending on these environmental factors (Zhang et al., 2010b). In absence of LD cycles, a subset of the dorsal neurons, the DN2 neurons, seem to entrain the entire network. While under LD cycles, the PDF positive LNs phase the DN2 groups by signalling light information via PDF/PDFR, the hierarchy is conversed under temperature cycles in constant darkness (Picot et al., 2009). The molecular signalling mechanisms are yet to be clarified.

\subsubsection{Sexual dimorphism and multiple oscillators}

With the determination of the D. melanogaster PDF sequence, Park and Hall were also able to show that $p d f$ is a sexual dimorphic gene, being more abundant in male flies (Park and Hall, 1998). The functional significance of this difference is yet unknown, but it is remarkable that PDF neurons are crucial for maintenance of male 
courtship behaviour (Fujii and Amrein, 2010). Also, male D. melanogaster show an earlier morning activity peak than females do (Helfrich-Förster et al., 2000; Helfrich-Förster, 2000). This corresponds well to the hypothesis that PDF regulates the morning activity peak, but only partially the evening peak (Rieger et al., 2006). The morning oscillator alone is sufficient to drive $24 \mathrm{~h}$ rhythms in DD (Grima et al., 2004). The PDF LNvs exert a dominant function in timing the $24 \mathrm{~h}$ rhythm and impose their rhythm on other brain pacemaker cells (Blanchardon et al., 2001). Using a novel electrochemical technique that silences PDF neuron electrical activity by the targeted expression of a $\mathrm{K}^{+}$channel, this hypothesis could be proven (Wu et al., 2008b). The transition of light to dark conditions does not require the LNvs (Dushay et al., 1989; Hardin et al., 1992), but is driven by the LNds (Grima et al., 2004), the fifth $p d f$-negative LNv and some of the DN (Stoleru et al., 2004; Rieger et al., 2006). There is, however, timing information exchange between LNvs and LNds (Stoleru et al., 2005); with the LNvs being the main pacemakers, contributing to both morning and evening peaks (Taghert and Shafer, 2006). PDF signals from the LNv morning cells affect the evening cells via PDFR activation (Choi et al., 2009; Lear et al., 2009).

Opposed to LNv action in DD, these cells cannot drive activity rhythms in constant light conditions, which are present only if there is also reduced CRYPTOCHROME (CRY) function (Picot et al., 2007). The $D$. melanogaster evening oscillator seems to receive light information from both the visual system and via CRY. PDF secreted by the l-LNvs is capable of phasing the evening oscillator molecular clock only when the CRY-function is absent or reduced; which is relevant on winter days. This PDF-function does not act via transcriptional control of per and is considered clock-independent. If both $p d f$ and cry are absent, flies show no evening activity peak at all in LD and reverse the peak of their freerun in LL from the evening to the morning. This is thought to be a consequence of antiphasic PER cycling in the evening oscillator, but not in the morning oscillator (Cusumano et al., 2009). Similar results were obtained for the relation between $p d f r$ and cry, additionally indicating that CRY can gate the PDF signal (Zhang et al., 2009). The division between morning and evening cells might be far more complex than previously thought, with a possibility of redundancy in the signalling system. The interactions of PDF and other signalling systems need further dissection (Lear et al., 2009).

\subsubsection{Influence on peripheral oscillators}

Besides the central brain molecular clock, several peripheral oscillators are involved in different circadian rhythms of the fruit fly. Ectopic expression of $p d f$ not only has an influence on activity, but also affects eclosion (Helfrich-Förster et al., 2000). Deciphering eclosion timing revealed the first peripheral fly oscillator under control of the accessory medulla clock. Gating of eclosion timing to the hours around dawn is regulated by a clock in the prothoracic gland, which in turn requires input from the fly's brain clock to maintain eclosion rhythms. This input signal is most likely PDF derived from the lateral neurons (Myers et al., 2003).

The fly's eye oscillator, the circadian rhythm in olfactory responses as well as the circadian egg-laying rhythm are all independent of pdf expression (Tanoue et al., 2004; Zhou et al., 2005; Howlader et al., 2006).

\subsubsection{Relation to the reproductive system}

Hamanaka et al. revealed that induction of reproductive diapause of female blowflies is regulated by PDF, thereby confining a reproductive function to the neuropeptide. Pars lateralis neurons induce reproductive diapause under short-day and low-temperature conditions. They receive synaptic input from PDFMe neurons, where PDF was observed in dense core vesicles, but not in clear synaptic vesicles. It is proposed that PDFMe neurons convey time or photoperiod information to the pars lateralis neurons (Hamanaka et al., 2005).

Additionally, circadian inputs to neurons producing prothoracicotropic hormone (PTTH) have been suggested for many insects. PTTH is related to the growth factor superfamily and is in all insects responsible for modulation of ecdysteroid synthesis by the prothoracic glands. It has been shown that $R$. prolixus PTTH release is under circadian control, and neuroanatomical data proves that PTTH neurons are in tight association with PDFpositive neurons. This association has been observed in larvae, continues in the animal's adult life and is even strengthened by additional PTTH and PDF neurons, but the presumed function of PDF as regulator of steroidogenesis in adults is yet to be elucidated (Vafopoulou et al., 2007, 2010).

Observed links between circadian locomotor activity and the endocrine system (Persson et al., 2001; Silvegren et al., 2005) ask for further study. Throughout development of the German cockroach, the circadian clock is completed in different stages, indicated by differential presence of PDF cells and projections. In nymphs of this species, some of the PDF-positive neurons also stain for corazonin, and vice versa. Interestingly, corazonin exerts pigment-dispersing actions in crayfish integument (Porras et al., 2003). It is suggested that PDF and corazonin work together in some of the output pathways of the circadian clock, possibly bridging the timing mechanism with the endocrine regulation of locomotion (Yang et al., 2009). It is noteworthy that in adult cockroaches, corazonin does not colocalise with, but is in close vicinity to PDF (Wen and Lee, 2008). Corazonin function seems less important in adults than it may be in nymphs (Yang et al., 2009), but there is a growing interest in this peptide as putative "alternating partner" for PDF in the regulation of clock-related functions (Boerjan et al., 2009).

\subsubsection{Geotaxis}

In $D$. melanogaster, the $p d f$ gene has been shown to influence geotactic behaviour. Interestingly, this is also true for another clock gene: cryptochrome. The influence of both genes on geotaxis is nevertheless clock independent, since deletion of the period gene shows no such effect. While $p d f$ is one of the multiple genes contributing to the overall geotactic phenotype, it is noteworthy that for this gene the effect on geotaxis is sex-related. In general, pdf null mutants show negative geotactic behaviour, meaning that they will fly against gravity (upwards) more than wild type flies do. Adding gradually more copies of the $p d f$ gene was related to a trend downward in geotactic behaviour for both sexes; whereas deletion of the pdf gene did not influence male geotactic behaviour, but significantly decreased geotactic behaviour of female flies (Toma et al., 2002). It is known that the LNvs mediate cocaine induced loss of negative geotaxis in adult flies, but not via PDF, indicating that another LNv neurotransmitter participates in this phenomenon (Tsai et al., 2004).

\subsubsection{Systemic action}

Over the years, research has focused on PDF actions in the central brain. Based on localisation patterns, a function for PDF in the regulation of both the blowfly's foregut and hindgut elements was proposed (Nässel et al., 1993), but we found no further records investigating this possibility. Also, an elaborate study of locust PDFAb neurons provides supporting evidence for endocrine functions of PDF outside the central nervous system, as the peptide was found to be present in the hemolymph. In the locust abdomen, PDF could modulate the muscle control of the genital organs (Persson et al., 2001). For certain, there are some interesting research issues waiting at the level of systemic PDF action. 


\subsection{A PDF receptor in insects}

A crucial breakthrough for functional PDF research was achieved when three groups simultaneously reported on the identification of the PDF receptor in the fruit fly $D$. melanogaster, which resulted in three names: $p d f r$, han (Korean for 'cold') and gop (groom of PDF) - we will further use pdfr. Mertens et al. found that PDFR is a class B G-protein coupled receptor (GPCR) that uses Gs to couple to adenylate cyclase and regulate cAMP levels. They could also show that neurofibromatosis1 ( $n f 1$ ), which acts downstream of $p d f$, increases response and sensitivity of the receptor. This led to the suggestion that NF1 might couple the receptor to adenylate cyclase, similar to its mammalian function (Mertens et al., 2005).

PDFR displays sequence homology to both mammalian $\mathrm{VPAC}_{2}$ and calcitonin receptors. Calcitonin and D. melanogaster calcitionin-like diuretic hormone 31 (DH31) could also elicit a response of PDFR, albeit to a lesser extent (Mertens et al., 2005). Interestingly, the in vivo s-LNv response to DH31 seems to partly depend on the PDFR because the molecule uses both PDFR and a specific DH31 receptor for signalling (Shafer et al., 2008).

As there were some differences in localisation patterns described in the first studies, additional experiments were needed for detailed information. Later expression experiments confined PDFR to all sLNvs, all LNds, to a lesser extent in the l-LNvs, in approximately half of the DN1, two DN3 and sometimes in one of the two DN2 (Shafer et al., 2008; Lear et al., 2009). About thirteen neuron pairs along the VNC of third instar larvae produced $p d f r$, but no embryonic expression was observed (Hyun et al., 2005). About one fifth of all pdfr product is present in the body; the rest is confined to the brain (Lear et al., 2005b). No diurnal pdfr RNA rhythm has been observed, suggesting that $p d f r$ is regulated at steady-state level by per (Mertens et al., 2005; Lear et al., 2005b). Because even the above reported studies are thought to produce incomplete data, in a recent study, transgene flies were generated, thus enabling PDFR localisation based on the gene's own regulatory elements. A most interesting finding emerging from this study is the detection of pdfr expression in non-clock brain cells and in the visual system (Im and Taghert, 2010). These data suggest that PDF may use non-neuronal cells to regulate the visual input to the circadian system, a suggestion that has also been made for the cricket (Saifullah and Tomioka, 2003).

A role as local neurohormone has been suggested since most pdf and pdfr cells do not seem to be synaptically connected (Lear et al., 2005b). In vivo cAMP imaging revealed that nearly all pacemaker cells, whether they express PDF or not, respond to PDF. The l-LNvs are unique in that they display no or minor responses to PDF. This technique furthermore proved that the effect of PDF on the s-LNvs is indeed direct and acts trough PDFR. Similarly, the effects of PDF on non-PDF expressing pacemaker cells are likely direct (Shafer et al., 2008).

Pdfr mutants phenotypically copy pdf null mutants: they show aberrant behavioural rhythmicity and have a severe negative geotaxis phenotype (Mertens et al., 2005). However, the absence of the morning peak does not seem to be stably associated with $\mathrm{pdfr}$ mutations, whereas an advanced evening activity is common to both $p d f$ and $p d f r$ mutant flies (Im and Taghert, 2010). The $p d f$ null mutant arrhythmicity in DD conditions could in a recent study be rescued by using membrane-anchored PDF molecules, most likely as a result of receptor activation in the dorsal evening cells (Choi et al., 2009). Pdfr mutants show a phase advance of PER oscillation (Lear et al., 2005b) similar to $p d f$ null mutants (Lin et al., 2004). The PDF signal can be prolonged by blocking SHIBIRE, a dynamin homologue that interferes with PDFR-mediated endocytosis. This receptor-mediated endocytosis influences the period of behavioural rhythms (Wülbeck et al., 2009).

It can be stated that since there is pdfr expression on the clock neurons themselves, $p d f$ must feed back on these neurons (Im and
Taghert, 2010). The mode of action might be via diffusion or indirect neuronal connections, as most pacemaker neurons contain only low receptor amounts (Mertens et al., 2005). The primary synchronisation role of PDF is furthermore confirmed by an experiment wherein reasonably normal activity patterns could be restored in $D$. melanogaster when expressing $p d f r$ in all clock neurons, but not in other pdfr-expressing neurons (Hyun et al., 2005). Looking in further detail, PDFR activation in the dorsal clock neurons appears important for rhythm generation, whereas PDF feedback to the LNvs has but a mild influence on circadian behaviour (Choi et al., 2009).

\subsection{Control of the PDF signal}

The PDF signal is regulated at different levels, resulting in a plethora of activating and inhibiting influences contributing to the overall PDF level. There is a general interplay between purely molecular and electrical signals.

\subsubsection{Molecular control}

Pdf-expression in D. melanogaster is stimulated by CLOCK (CLK) and posttranscriptionally inhibited by VRILLE (VRI) (Table 4). VRI, a bZIP transcription factor with a developmental role (George and Terracol, 1997), is itself a clock-controlled gene in the fruit fly (Blau and Young, 1999). It appears that CLK is only required for pdf expression in the larval LN and in the s-LNvs, since a mutation in the clk gene does not affect the pdf expression in l-LNvs and PDFAb neurons (Park et al., 2000). The heterodimerous partner of CLK, CYCLE, exerts similar but less severe effects on $p d f$ expression. Mutations in both genes are additionally accompanied by developmental defects of PDF neurons, yet clock and cycle seem to influence $p d f$ in an indirect fashion (Park et al., 2000). Interestingly, PDF peptide levels are influenced by mutations in either period or timeless, demonstrating a posttranslational, circadian regulation: PER and TIM could establish a temporal release gating for PDF, acting - in contrast to other per and tim phenotypes - in a counterproductive way (Park et al., 2000) (Table 4).

PDP1 $\varepsilon$ is one of the seven isoforms of the D. melanogaster pdp1 gene and is thought to be involved in both the central timing mechanism of the circadian clock and in output. PDP1 1 and VRI have opposite effects on clock transcription, thereby indirectly influencing $p d f$ transcription (Table 4 ). Restoring clk expression in a $p d p 1 \varepsilon$ mutant background remarkably is unable to restore either $p d f$ expression or behavioural rhythms, indicating that the effect of PDP1 $\varepsilon$ on PDF is not strictly through clk (Zheng et al., 2009).

In a study of the neurofibromatosis- 1 gene it is suggested that binding of PDF to its receptor may influence the Ras/MAPK pathway that is also regulated by neurofibromin, the $n f 1$ gene product. MAPK activity cycles in the dorsal brain and participates in behavioural rhythmicity (Williams et al., 2001).

Looking upstream of $p d f$, there is some evidence that the disco gene controls the expression of clock genes: whereas it is usually assumed that the disco ${ }^{1}$ mutation eliminates the LN from the brain (Helfrich-Förster and Homberg, 1993), PDF- and PER-negative lateral neurons have been detected in disco ${ }^{1}$ mutants (Blanchardon et al., 2001). The earlier results are based on the use of PDF as a marker for the presence of the LN. Using a gal1118-driven GFP marker, it could be shown that most disco ${ }^{1}$ mutants still possess at least one LN, but do not stain for PDF or PER (Blanchardon et al., 2001).

The LARK mRNA-binding protein mediates the temporal regulation of eclosion (Newby and Jackson, 1993) and has a general role in neuron excitability. Interestingly, when overexpressed only in the PDF-positive LNvs, it will act different in small and large neuron subgroups, and also in relation to the timing of overexpression. Overexpression during development influences the morphology of the s-LNvs, but not the l-LNvs: under 
Table 4

Intracellular molecular interactions regulating PDF levels $( \pm$ : in- or decrease of $p d f$ expression or PDF presence). Indirect actions of VRI and PDP- $1 \varepsilon$ requiring $c l k$ have been described. The mode of operation of other actions is yet to be elucidated.

\begin{tabular}{llll}
\hline & via $c l k$ & Not via $c l k$ & \\
\cline { 3 - 4 } & & Transcriptional & Posttranscriptional \\
\hline CLK & & + & \\
CYC & & + & - \\
VRI & - & & \\
PDP1 $\varepsilon$ & + & Other than via clk & Influence on PDF cycling \\
PER & & & Influence on PDF cycling \\
TIM & & &
\end{tabular}

these conditions, the s-LNv projections fail to reach their targets or the entire s-LNvs may even be eliminated. On the other hand, when overexpression is present in adult life, neuron morphology remains unaltered. Adult PER cycling is furthermore perturbed only in the 1LNvs, whereas PDP1 $\varepsilon$ cycling is altered in the s-LNvs (Huang et al., 2009). The observed locomotor phenotype may indicate aberrant PDF function, but this remains to be investigated.

\subsubsection{Electrical activity}

While the LNvs synchronise oscillations in downstream neurons, their proper membrane excitability is regulated upstream and gates PDF release. As a consequence, excitability of the LNvs is critical for coherent rhythms; revealing a combined electrical and neuropeptide regulation of the clock neurons (Nitabach et al., 2006; Wu et al., 2008a). In the housefly, for example, PDF release is triggered by depolarisation (Miśkiewicz et al., 2008).

A potential candidate for electrical upstream PDF neuron regulation is SHAW, an endogenous neuronal potassium channel that regulates the resting membrane potential. SHAW probably modulates the electrical activity of clock neurons, amongst which the DN seem the major target. Changing SHAW levels in the DN proved to have the greatest influence on both locomotor activity as well as rhythmic PDF accumulation in the LNv terminals. Thus in turn, the DNs affect the rhythmic release of PDF (Hodge and Stanewsky, 2008). It should however be noted that many shawexpressing cells also contain the PDF receptor; the molecular action of SHAW and its relation to PDF need further clarification.

Another candidate for PDF release regulation is the ion channel NARROW ABDOMEN (NA). Na mutants show elevated PDF levels in the dorsal projections of the s-LNvs, even under conditions in which PER is largely unaffected, indicating its output function (Lear et al., 2005a). A recent study also revealed the necessity of na expression in a subset of the posterior dorsal neurons 1 (DN1p) for mediating photic responses and morning anticipatory behaviour. As pdf receptor expression in these neurons is equally required for this behaviour, it has been proposed that the DN1p neurons comprise the nexus of PDf and photic (NA) signalling (Zhang et al., 2010a).

In addition, both the $D$. melanogaster slowpoke and slowpoke binding protein (slob) genes have been associated with PDF. SLOB is a component of a dynamic protein complex that modulates the activity of the SLOWPOKE $\mathrm{Ca}^{2+}$-activated $\mathrm{K}^{+}$-channel and thus affects membrane excitability. As cyclic release of neuropeptides may be a consequence of daily changes in membrane potential and SLOB oscillates in photoreceptor nuclei and pars intercerebralis neuron cytoplasm, this protein is thought to be involved in the circadian system. In pdf null mutant flies, SLOB expression is furthermore reduced in pars intercerebralis neurons in the vicinity of the normally PDF-filled s-LNv terminals, implicating PDF as an upstream activator. PDF-mediated SLOB regulation probably acts via dorsal action of the l-LNvs (Jaramillo et al., 2004). Interestingly, the slowpoke mutant displays arrhythmic activity behaviour, probably as a result of aberrant PDF accumulation or release in the dorsal protocerebrum (Fernández et al., 2007).
There are some interesting aspects on PDF action when studying hyperexcitable versus silenced LNvs. Targeted expression of a voltage-gated sodium channel (NaChBac) in the LNvs of $D$. melanogaster renders them hyperexcitable and results in apparent asynchronous molecular oscillations after transfer to DD, reminiscent of PDF action (Nitabach et al., 2006). Long term DD observations of flies with such perturbed LNv activity contrarily showed that the circadian circuit evolved towards a new rhythmic balance. Not only PDF-dependent, but also PDF-independent factors thereby contribute to a circadian circuit-wide regulation of molecular oscillations and electrical activity of the LNvs, coordinating the different outputs (Sheeba et al., 2008c). When the LNvs are conversely silenced by targeted expression of a potassium channel, flies phenocopy the $p d f$ null mutant flies both in behaviour and molecular oscillations in non-LNv clock neurons, except for a complete abolition of freerunning oscillations in the LNvs themselves. This suggests that the residual LNv oscillations in $p d f$ null mutants have no functional effect; therefore the LNvs do normally not use PDF-independent signalling mechanisms (Wu et al., 2008a), meaning that this signal must be derived from other cells.

\subsubsection{Release and inactivation}

The tetanus-toxin light chain (TeTxLC) blocks chemical synaptic transmission by targeting synaptobrevin, a molecule co-responsible for membrane fusion in exocytosis of secretory vesicles. When TeTxLC is expressed under control of the pdf promoter, the behavioural activity pattern of flies showed little changes (Kaneko et al., 2000). Considering the evidence for the importance of the $p d f$ expressing cells in rhythmic behaviour (Helfrich-Förster, 1998; Stanewsky et al., 1998; Renn et al., 1999), it is most likely that the TeTxLC does not sufficiently block $p d f$ release in $D$. melanogaster (Kaneko et al., 2000); meaning that PDF transmission does not use synaptobrevin-dependent signalling (Blanchardon et al., 2001).

After its release from the presynaptic site and action on target neurons, PDF is rendered inactive through hydrolysis by the extracellular peptidase neprilysin. The D. melanogaster genome harbours 25 neprilysin-like molecules, it still needs to be revealed which one(s) is (are) responsible for this action (Isaac et al., 2007).

\section{Pigment dispersing factor in nematodes}

\subsection{The discovery and diversity of pigment dispersing factor peptides in nematodes}

Caenorhabditis elegans is the best studied representative among nematodes. C. elegans exhibits a clear circadian rhythm in activity and in resistance to osmotic and oxidative stress (Saigusa et al., 2002; Hasegawa et al., 2005; Simonetta and Golombek, 2007; Simonetta et al., 2008; Simonetta et al., 2009). The C. elegans genome contains homologues of many of the central regulators of circadian timing in D. melanogaster, like lin-42( p period), tim-1 ( timeless), kin20 ( $\sim$ doubletime), sma-9 ( clock), aha-1 ( cycle) and atf-2 ( vrille). Most of these genes, however, are involved in the timing of development. The general view stipulates that the core of the circadian clock in C. elegans is composed differently than that of insects (Jeon et al., 1999; Chan et al., 2003; Banerjee et al., 2005; Hasegawa et al., 2005).

Our group recently added PDF to the list of clock homologues by means of a reverse pharmacological screen. The $C$. elegans PDF system consists of three different PDF peptides called PDF-1a, PDF$1 \mathrm{~b}$ and PDF-2, and three PDF receptors called PDFR-1a, PDFR-1b and PDFR-1c. All three $C$. elegans PDF peptides were able to activate each of the three $C$. elegans receptors in a dose-dependent manner, albeit with different affinities (Janssen et al., 2008, 2009).

Similarly to crustacean PDH and insect PDF, originates the nematode PDF peptide from a larger precursor molecule consisting 
of a signal peptide, a linking peptide and the mature PDF flanked by dibasic cleavage sites.

A tBLASTn analysis of the Ce-PDF- 1 and Ce-PDF- 2 precursors revealed an extremely strong conservation within the phylum of nematodes wherein four (Rhabditina, Tylenchina, Spirurina and Dorylaimia) of the five nematode clades contain species that have clear pdf orthologues (Table 5) (Parkinson et al., 2004; Janssen et al., 2009). Based on amino acid sequence, nematode PDF-like peptides are more related to $\beta-\mathrm{PDH}$ than to $\alpha-\mathrm{PDH}$. They are however more distantly related to $\beta$-PDH than the insect PDF peptides and contain 20-22 amino acids instead of 18 .

\subsection{Pigment dispersing factor localisation}

Spatial expression patterns of $C$. elegans PDF were examined using translational green fluorescent protein (GFP) reporter constructs. The $C$. elegans PDF-1 precursor gene (encoding both PDF-1a and PDF-1b peptides) is expressed throughout postembryonic life in interneurons, (chemo)sensory neurons and motor neurons. Also a few non-neuronal tissues like rectal gland cells and intestinal rectal valve cells express these peptides. Pdf-2 expression was similar and could be observed during postembryonic life in interneurons, (chemo)sensory neurons, motor neurons and also

Table 5

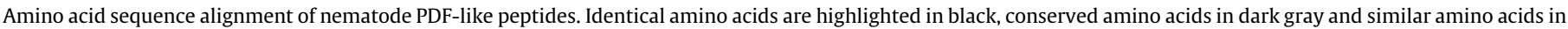
light gray.

\begin{tabular}{|c|c|c|}
\hline Species & Peptide sequence & Reference \\
\hline \multicolumn{3}{|l|}{ Nematode PDF-1a } \\
\hline $\begin{array}{l}\text { Caenorhabditis elegans } \\
\text { Caenorhabditis briggsae* } \\
\text { Caenorhabditis remanei* } \\
\text { Caenorhabditis brenneri* } \\
\text { Caenorhabditis japonica* } \\
\text { Heterorhabditis bacteriophora* } \\
\text { Pristionchus pacificus* } \\
\text { Ancylostoma caninum* } \\
\text { Ancylostoma ceylanicum* } \\
\text { Necator americanus* } \\
\text { Teladorsagia circumcincta* } \\
\text { Dictyocaulus viviparus* } \\
\text { Srongyloides stercoralis* } \\
\text { Bursaphelenchus xylophilus* } \\
\text { Ascaris suum* } \\
\text { Ditylenchus africanus* }\end{array}$ & 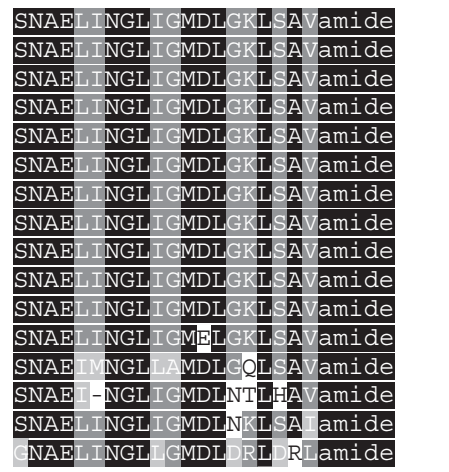 & (Janssen et al., 2008; Janssen et al., 2009) \\
\hline \multicolumn{3}{|l|}{ Nematode PDF-1b } \\
\hline $\begin{array}{l}\text { Caenorhabditis elegans } \\
\text { Caenorhabditis briggsae* } \\
\text { Caenorhabditis remanei* } \\
\text { Caenorhabditis brenneri* } \\
\text { Caenorhabditis japonica* } \\
\text { Heterorhabditis bacteriophora* } \\
\text { Pristionchus pacificus* } \\
\text { Ancylostoma caninum* } \\
\text { Ancylostoma ceylanicum* } \\
\text { Necator americanus* } \\
\text { Teladorsagia circumcincta* } \\
\text { Dictyocaulus viviparus* } \\
\text { Strongyloides stercoralis* } \\
\text { Bursaphelenchus xylophilus* } \\
\text { Ascaris suum* } \\
\text { Onchocerca volvulus* } \\
\text { Trichinella spiralis* }\end{array}$ & 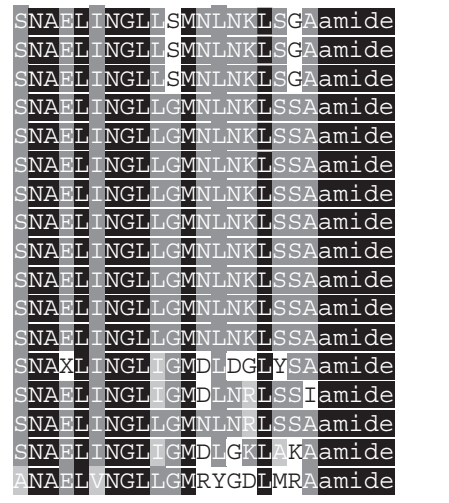 & (Janssen et al., 2008; Janssen et al., 2009) \\
\hline \multicolumn{3}{|l|}{ Nematode PDF-2 } \\
\hline $\begin{array}{l}\text { Caenorhabditis elegans } \\
\text { Caenorhabditis ramenei* } \\
\text { Caenorhabditis. brenneri* } \\
\text { Caenorhabditis. japonica* } \\
\text { Caenorhabditis briggsae } \\
\text { Ascaris suum* } \\
\text { Bursaphelenchus xylophilus* } \\
\text { Necator americanus* } \\
\text { Ancylostoma caninum* } \\
\text { Ostertagia ostertagi* } \\
\text { Ancylostoma ceylanicum* } \\
\text { Teladorsagia circumcincta* } \\
\text { Nippostrongylus brasiliensis* } \\
\text { Brugia malayi* } \\
\text { Meloidogyne javanica* } \\
\text { Meloidogyne incognita* } \\
\text { Meloidogyne chitwoodi* } \\
\text { Meloidogyne hapla* }\end{array}$ & 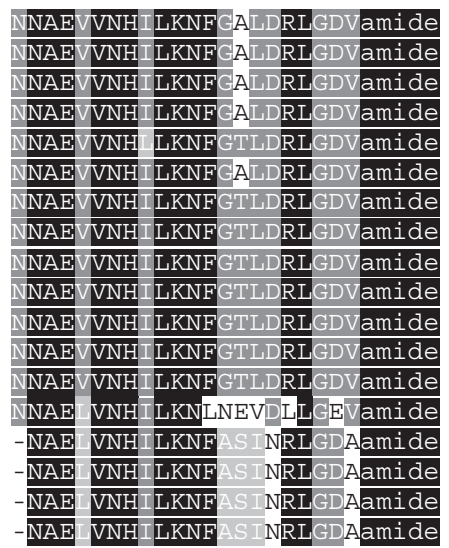 & $\begin{array}{l}\text { (Janssen et al., 2008; Janssen et al., 2009) } \\
\text { (Husson et al., 2009) }\end{array}$ \\
\hline
\end{tabular}

*Amino acid sequence derived from tBLASTn (ClustalW2 and BOXSHADE 3.21). 
in rectal gland cells, intestine-rectal valve cells and three additional posterior arcade cells in the head that line the extreme inside edge of the buccal cavity. Apart from GFP fluorescence in somata, also several dendrites and axons showed $p d f$ expression indicating that the PDF peptides fulfil a possible role in neuromodulation and/or transmission (Janssen et al., 2009).

\subsection{Function and regulation}

Almost all PDF neurons in C. elegans play a role in the sensing and integration of environmental stimuli such as mechanosensation, oxygen sensing and chemosensation or in the control of locomotion (Janssen et al., 2009). Mutants lacking PDF-1a and b display a severely altered locomotor behaviour manifested in a decreased moving speed, an increased reversal frequency and an increased frequency of directional changes. Overexpression of $p d f$ 2 phenocopies the locomotor defects of the $p d f-1$ deletion mutant, suggesting that they elicit opposite effects on locomotion (Janssen et al., 2008). The individual PDF peptides do not seem to influence each others expression levels (Janssen et al., 2009). Although $p d f-1$ mutants show an obvious locomotor phenotype, it has so far not been demonstrated that the PDF peptides are also involved in the regulation of circadian activity. Analogous to the $D$. melanogaster PDF system, C. elegans shows no daily variations in $p d f$ ( $p d f-1$ and $p d f-2$ ) gene expression, as determined by RT-PCR (Janssen et al., 2009). Whether or not PDF levels fluctuate at protein level, has not yet been investigated. C. elegans pdf expression seems to be positively regulated at the mRNA level by two clock related proteins, i.e. ATF-2 $(\sim$ D. melanogaster VRILLE) and CES-2 $(\sim D$. melanogaster PAR domain protein 1; PDP1E) (Janssen et al., 2009). Atf-2 en ces-2 both encode bZIP transcription factors which have been suggested to regulate developmental cell fate in a temporal and spatial way (Wang et al., 2006; Hatzold and Conradt, 2008). In yeast two-hybrid experiments, ATF-2 and CES-2 were able to physically interact and form functional heterodimers that regulate the temporal transcription of certain genes e.g. lin-48. As described in Section 3.4.1, D. melanogaster VRILLE and PDP1 $\varepsilon$ regulate $p d f$ expression respectively in a negative and positive way partially via CLOCK.

\subsection{PDF receptors in nematodes}

C. elegans contains three $G$ protein-coupled PDF receptors which belong to the class B (secretin) type of GPCRs. These three receptors are in fact three isoforms encoded by the same gene, called pdfr-1. PDF-2 is the most potent ligand of the PDF receptor isoforms $\mathrm{a}$ and $\mathrm{b}$ (Janssen et al., 2008). The C. elegans PDF receptors are expressed in several sensory- and motorneurons and in all body wall muscles (Janssen et al., 2008).

Class B GPCRs, including the D. melanogaster PDF receptor, typically signal through adenylate cyclase via $\mathrm{G} \alpha_{\mathrm{s} / \mathrm{i}}$ (Mertens et al., 2005). This is also the case for the C. elegans PDF receptor as was demonstrated in an in vitro CRE-luciferase reporter assay in HEK293 cells. Both PDFR-1a and PDFR-1b seem to signal through $\mathrm{G} \alpha_{s}$, whereas PDFR-1c seems to signal through $\mathrm{G} \alpha_{\mathrm{i}}$ (Janssen et al., 2008).

\section{Homology to the vertebrate system}

For insects, both the organisation of the circadian system in which PDF acts and the molecular actions of the neuropeptide are often compared to the vertebrate system (Fig. 6). As this comparison is not common for crustacean literature and too premature for nematodes, following introductory description will focus on the present knowledge for insect en vertebrate PDF signalling.

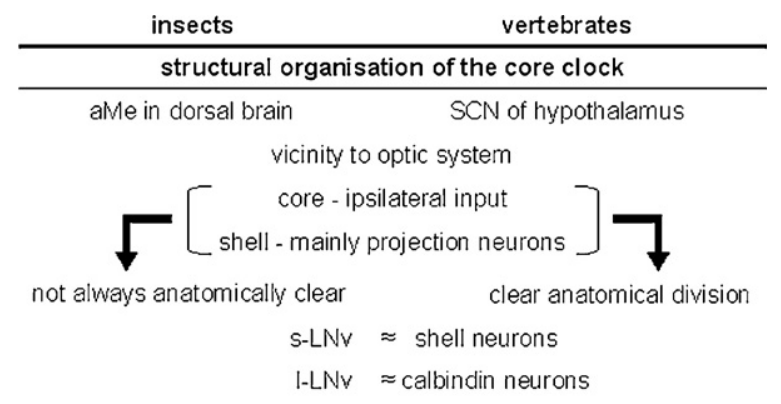

multiphasic clock organisation: different effects on different cells

signalling uses cAMP \& ion channels

\begin{tabular}{l}
\hline function \\
\hline maintenance of individual oscillator synchrony \\
regulation of locomotor and endocrine rhythms
\end{tabular}

Fig. 6. Introductory scheme for comparison of core clock structure and PDF/VIP action between insects and vertebrates. (aMe, accessory medulla; SCN, suprachiasmatic nucleus; s/l-LNv, small/large ventrolateral neurons; VIP, vasoactive intestinal peptide) For detailed information: see text.

\subsection{Structural organisation}

The dorsal brain is an important region with regard to circadian timing in all insects. Although there are some insect species that seem to have the dorsal brain clock as master, the location of the master clock is generally the aMe. In mammals, the suprachiasmatic nuclei (SCN) of the hypothalamus comprise the master clock. The SCN and aMe can be compared on many levels. They are both in close vicinity to the optic system. The structural organisation of mammalian and insect central clocks is alike in that they both consist of a core that gets ipsilateral input and a shell that mainly contains projection neurons. This structural division of the SCN is based on a different cell architecture: the ventrolateral core consists of rather loosely associated, spherical neurons with many afferent fibers; while the dorsomedial shell comprises closely packed, elongated neurons with many efferent fibers. Although such split organisation is clearly visible for the well characterised cockroach aMe, it must be noted that the flies' aMe does not show an evident anatomical division. In the cockroach, the core contains tight neuropil knots named noduli, and the shell - or internodular neuropil - lies around and inbetween these structures. Similar to the SCN, the aMe core gets input from the ipsilateral photic system and the shell provides many efferent fibers. For mammals as well as for insects, the structural division is associated with different functionality for core and shell neurons. SCN core neurons contain, amongst others, vasoactive intestinal peptide (VIP) and calbindin. Calbindin neurons may be important in gating photic signals and are the possible counterparts of the PDF-positive l-LNv. Vasopressin is expressed in the shell neurons and acts as an output peptide. The Drosophila s-LNv are thought to be similar to the shell neurons. Additionally, both aMe and SCN communicate via diffusible substances and rely on glia cells for function (Helfrich-Förster, 2000; Helfrich-Förster, 2004). 


\subsection{VIP/VPAC 2 resembles $P D F / P D F R$}

Whereas the PDFR shows sequence homology to $\mathrm{VPAC}_{2}$, which is the mammalian receptor for VIP and PACAP; no sequence homologue for PDF exists in vertebrates (Mertens et al., 2005; Vosko et al., 2007). VIP is nevertheless the best candidate based on function. While PACAP is able to activate the D. melanogaster PDFR (Mertens et al., 2005), this has never been tested for VIP, nor are there any records of PDF action on $\mathrm{VPAC}_{2}$.

Vasoactive intestinal peptide is synthesized in the ventrolateral region of the $\mathrm{SCN}$, which is innervated by retinal cells. In contrast to the fly PDF/PDFR levels, both VIP and VPAC 2 mRNA show daily cycling (Vosko et al., 2007). VIP is involved in photic phase shifting of the SCN clock and phase-advances the release of arginine vasopressin (AVP), which is important in the output of the circadian clock. It also induces Period gene transcription (Harmar et al., 2002; Aton and Herzog, 2005). After release, both PDF and VIP are degraded by endopeptidases: neprilysin and neprilysin/ kallikrein, respectively (Isaac et al., 2007).

In mammals, $\mathrm{VPAC}_{2}$-cells include half of the VIPergic cells and almost all AVP-neurons of the dorsal SCN. VIP/VPAC 2 is needed for synchrony between SCN cells as well as within individual SCN neurons. The $\mathrm{VIP} / \mathrm{VPAC}_{2}$ signalling system is furthermore of major importance for coupling the oscillator to the environment. VIP may even feed back to regulate VIPergic cells, as they express VPAC 2 . Both $V I P^{-/-}$and $V_{i p r} 2^{-/-}$mice show rhythm deficiencies that reflect their inabilities to maintain amplitude and circadian synchrony (Harmar et al., 2002; Aton and Herzog, 2005; Vosko et al., 2007). Similarly to PDF (Mertens et al., 2005), VIP binding leads to cAMP increases. VIP may modulate GABA-mediated transmission in the SCN in a cAMP-dependent way, thereby maintaining synchrony between SCN neurons (Vosko et al., 2007). For PDF, different effects on different clock neurons have been described; such a multiphasic clock organisation has also been reported for mammals (Yoshii et al., 2009).

VIP also seems to influence firing rates of a subpopulation of SCN neurons by regulating ion currents (Vosko et al., 2007). Drosophila and mammalian circadian neuron electrical characteristics closely resemble each other (Sheeba et al., 2008b); homologous ion channels have been reported to be involved in both systems (Hodge and Stanewsky, 2008).

Taking the focus away from locomotor activity, the insect PDFpositive clock cells as well as the mammalian SCN are both related to endocrine rhythms. VIP has been reported to play a role in the temporal regulation of gonadotropin-releasing hormone neurons and of the hypothalamic-pituitary-adrenal axis (Vafopoulou et al., 2007; Vosko et al., 2007).

\section{Concluding remarks}

In this review, we opted to cover the literature on the pigment dispersing-like molecular signalling systems. Pigment dispersinglike systems have been studied extensively over the past decades, and the rich variety of physiological processes in part regulated by these mechanisms is an example of the complexity of regulation and communication in living organisms.

Within the PDH and PDF precursor molecules the mature peptides are well conserved, whereas the PDH/PDF associated peptide which is also present in the precursor is poorly conserved and of unknown function. Most pigment dispersing-like precursors contain a signal peptide targeting them to the secretion pathway, but a nuclear localisation sequence has also been described.

Looking in detail, no general localisation patterns can be derived for these peptides, probably reflecting species-specific differences in function as well. The system is nevertheless invariably associated with the visual system, optimally localised to modify visual information. Whereas the functions of pigment dispersing hormone-like molecules in the central nervous system are widely studied, the future is bound to reveal more information on the endocrine actions of this pleiotropic molecule. PDH has been shown to regulate crustacean colour changes and retinal sensitivity, thus influencing the darkening of the integument and acting as a natural pair of sunglasses for the eyes. In insects, the involvement of PDF in the circadian clock is intensively studied, as different research teams try to precisely describe the functions of the molecule herein. Also, non-circadian related processes like the peripheral oscillator regulating eclosion timing are influenced by PDF. It is also interesting that D. melanogaster PDF levels are a sexdimorphic trait, possibly beneficial in reproductive behaviour. Associations with reproduction are present in different species, for example in the regulation of the induction of reproductive diapause of female blowflies. Other processes such as behavioural arousal and sleep, and geotaxis are also influenced by this neuropeptide. In nematodes, the only PDF-function so far described is related to locomotory behaviour.

Summarising the literature reported on one single molecule, reveals the diversity of amino acid sequences and functions among different species and also within species. Keeping this in mind, researchers from diverse fields can benefit from such knowledge, which may reveal molecular crossroads and interplays between studied processes. Further research in different species will not only provide deeper insight into the diversity of regulating and modulating systems, it will also reveal the evolution of this neuropeptidergic signalling system. The quest for knowledge continues.

\section{Acknowledgements}

The authors would like to thank J. Puttemans for the excellent assistance and creation of the figures. We are grateful to the reviewers for their critical reading of the manuscript. EM benefits from a PhD grant of the Institute for Promotion of Innovation through science and Technology in Flanders (IWT-Vlaanderen), LT and TJ benefit grants from the Scientific Research Foundation Flanders (FWO-Vlaanderen).

\section{References}

Abdelsalam, S., Uemura, H., Umezaki, Y., Saifullah, A.S.M., Shimohigashi, M., Tomioka, K., 2008. Characterization of PDF-immunoreactive neurons in the optic lobe and cerebral lobe of the cricket, Gryllus bimaculatus. J. Insect Physiol. 54, 1205-1212.

Aréchiga, H., Fernández-Quiróz, F., de Miguel, F.F., Rodríguez-Sosa, L., 1993. The circadian system of crustaceans. Chronobiol. Int. 10, 1-19.

Aréchiga, H., Mena, F., 1975. Circadian variations of hormonal content in nervoussystem of crayfish. Comp. Biochem. Physiol. A: Physiol. 52, 581-584.

Aréchiga, H., Rodriguez-Sosa, L., 1998. Circadian clock function in isolated eyestalk tissue of crayfish. In: Proceedings of the Royal Society of London Series BBiological Sciences, vol. 265. pp. 1819-1823.

Aton, S.J., Herzog, E.D., 2005. Come together, right now: synchronization of rhythms in a mammalian circadian clock. Neuron 48, 531-534.

Bahn, J.H., Lee, G., Park, J.H., 2009. Comparative analysis of Pdf-mediated circadian behaviors between Drosophila melanogaster and D. virilis. Genetics 181, 965-975.

Balys, M., Pyza, E., 2001. Localization of the clock controlling circadian rhythms in the first neuropile of the optic lobe in the housefly. J. Exp. Biol. 204, 33033310.

Banerjee, D., Kwok, A., Lin, S.Y., Slack, F.J., 2005. Developmental timing in C. elegans is regulated by kin-20 and tim-1, homologs of core circadian clock genes. Dev. Cell 8, 287-295.

Barnwell, F.H., 1963. Observations on daily and tidal rhythms in some fiddler crabs from equatorial Brazil. Biol. Bull. 125 399-\&.

Bennitt, R., 1932b. Diurnal rhythm in the proximal pigment cells or the crayfish retina. Physiol. Zool. 5, 65-68.

Bennitt, R., 1932a. Physiological inter-relationship in the eyes of decapod crustacea. Physiol. Zool. 5, 49-64.

Blanchardon, E., Grima, B., Klarsfeld, A., Chélot, E., Hardin, P.E., Préat, T., Rouyer, F., 2001. Defining the role of Drosophila lateral neurons in the control of circadian rhythms in motor activity and eclosion by targeted genetic ablation and PERIOD protein overexpression. Euro. J. Neurosci. 13, 871-888. 
Blau, J., Young, M.W., 1999. Cycling vrille expression is required for a functional Drosophila clock. Cell 99, 661-671.

Bloch, G., Solomon, S.M., Robinson, G.E., Fahrbach, S.E., 2003. Patterns of PERIOD and pigment-dispersing hormone immunoreactivity in the brain of the European honeybee (Apis mellifera): age- and time-related plasticity. J. Comp. Neurol. 464, 269-284.

Boerjan, B., Cardoen, D., Bogaerts, A., Landuyt, B., Schoofs, L., Verleyen, P., 2010. Mass spectrometric profiling of (neuro)-peptides in the worker honeybee, Apis mellifera. Neuropharmacology 58, 248-258.

Boerjan, B., Verleyen, P., Huybrechts, J., Schoofs, L., De Loof, A., 2009. In search for a common denominator for the diverse functions of arthropod corazonin: a role in the physiology of stress? Gen. Comp. Endocrinol. 66, 222-233.

Böhm, H., Dybek, E., Heinzel, H.G., 2001. Anatomy and in vivo activity of neurons connecting the crustacean stomatogastric nervous system to the brain. J. Comp. Physiol. A: Sens. Neural Behav. Physiol. 187, 393-403.

Brown, F.A., 1950. Studies on the physiology of Uca red chromatophores. Biol. Bull. $98,218-226$.

Bulau, P., Meisen, I., Schmitz, T., Keller, R., Peter-Katalinić, J., 2004. Identification of neuropeptides from the sinus gland of the crayfish Orconectes limosus using nanoscale on-line liquid chromatography tandem mass spectrometry. Mol. Cell. Proteomics 3, 558-564.

Chan, R.C., Chan, A., Jeon, M., Wu, T.F., Pasqualone, D., Rougvie, A.E., Meyer, B.J., 2003. Chromosome cohesion is regulated by a clock gene paralogue TIM- 1 . Nature 423, 1002-1009.

Chen, D.M., Christianson, J.S., Sapp, R.J., Stark, W.S., 1992. Visual receptor cycle in normal and period mutant Drosophila: microspectrophotometry, electrophysiology, and ultrastructural morphometry. Vis. Neurosci. 9, 125-135.

Choi, C., Fortin, J.P., McCarthy, E.V., Oksman, L., Kopin, A.S., Nitabach, M.N., 2009. Cellular dissection of circadian peptide signals with genetically encoded membrane-tethered ligands. Curr. Biol. 19, 1167-1175.

Christie, A.E., Stemmler, E.A., Dickinson, P.S., 2010. Crustacean neuropeptides. Cell. Mol. Life Sci. Epub ahead of print

Chuman, Y., Matsushima, A., Sato, S., Tomioka, K., Tominaga, Y., Meinertzhagen, I.A., Shimohigashi, Y., Shimohigashi, M., 2002. cDNA cloning and nuclear localization of the cireadian neuropeptide designated as pigment-dispersing factor PDF in the cricket Gryllus bimaculatus. J. Biochem. 131, 895-903.

Chung, J.S., Webster, S.G., 2004. Expression and release patterns of neuropeptides during embryonic development and hatching of the green shore crab, Carcinus maenas. Development 131, 4751-4761.

Cusumano, P., Klarsfeld, A., Chélot, E., Picot, M., Richier, B., Rouyer, F., 2009. PDFmodulated visual inputs and cryptochrome define diurnal behavior in Drosophila. Nat. Neurosci. 12, 1431-1437.

De Kleijn, D.P.V., Van Herp, F., 1995. Molecular biology of neurohormone precursors in the eyestalk of Crustacea. Comp. Biochem. Physiol. B: Biochem. Mol. Biol. 112, 573-579.

De Kleijn, D.P.V., Linck, B., Klein, J.M., Weidemann, W.M., Keller, R., VanHerp, F., 1993. Structure and localization of messenger-rna encoding a pigment dispersing hormone (PDH) in the eyestalk of the crayfish Orconectes limosus. FEBS Lett. $321,251-255$.

Desmoucelles-Carette, C., Sellos, D., Van Worhmoudt, A., 1998. Molecular cloning of the pigment dispersing hormone in a crustacean. Ann. N. Y. Acad. Sci. 839, 395396.

Desmoucelles-Carette, C., Sellos, D., VanWormhoudt, A., 1996. Molecular cloning of the precursors of pigment dispersing hormone in crustaceans. Biochem. Biophys. Res. Commun. 221, 739-743.

Detto, T., Hemmi, J.M., Backwell, P.R., 2008. Colouration and colour changes of the fiddler crab, Uca capricornis: a descriptive study. PLoS One 3, e1629.

Dircksen, H., Zahnow, C.A., Gaus, G., Keller, R., Rao, K.R., Riehm, J.P., 1987. The ultrastructure of nerve-endings containing pigment-dispersing hormone (PDH) in crustacean sinus glands - identification by an antiserum against a synthetic PDH. Cell Tissue Res. 250, 377-387.

Dores, R.M., Herman, W.S., 1981. Insect chromatophorotropic factors: the isolation of polypeptides from Periplaneta americana and Apis mellifera with melanophore-dispersing activity in the crustacean, Uca pugilator. Gen. Comp. Endocrinol. 43, 76-84.

Dushay, M.S., Rosbash, M., Hall, J.C., 1989. The disconnected visual system mutations in Drosophila melanogaster drastically disrupt circadian rhythms. J. Biol. Rhythms 4, 1-27.

Emery, P., So, W.V., Kaneko, M., Hall, J.C., Rosbash, M., 1998. CRY, a Drosophila clock and light-regulated cryptochrome, is a major contributor to circadian rhythm resetting and photosensitivity. Cell 95, 669-679.

Fernández, M.P., Berni, J., Ceriani, M.F., 2008. Circadian remodeling of neuronal circuits involved in rhythmic behavior. Plos Biol. 6, 518-524.

Fernández, M.P., Chu, J., Villella, A., Atkinson, N., Kay, S.A., Ceriani, M.F., 2007. Impaired clock output by altered connectivity in the circadian network. Proc. Natl. Acad. Sci. U.S.A. 104, 5650-5655.

Fernlund, P., 1976. Structure of a light-adapting hormone from shrimp, Pandalus borealis. Biochim. Biophys. Acta 439, 17-25.

Fingerman, M., 1955. Persistent daily and tidal rhythms of color change in Callinectes sapidus. Biol. Bull. 109, 255-264.

Fingerman, M., 1970. Comparative physiology: chromatophores. Ann. Rev. Physiol. $32,345-372$.

Fingerman, M., Philpott, L., Nagabhushanam, R., 1962. Photomechanical responses of proximal pigment in palaemonetes and orconectes. Biol. Bull. 123 121-\&.
Fu, Q., Goy, M.F., Li, L.J., 2005a. Identification of neuropeptides from the decapod crustacean sinus glands using nanoscale liquid chromatography tandem mass spectrometry. Biochem. Biophys. Res. Commun. 337, 765-778.

Fu, Q., Kutz, K.K., Schmidt, J.J., Hsu, Y.W.A., Messinger, D.I., Cain, S.D., De la Iglesia, H.O., Christie, A.E., Li, L.J., 2005b. Hormone complement of the Cancer productus sinus gland and pericardial organ: an anatomical and mass spectrometric investigation. J. Comp. Neurol. 493, 607-626.

Fujii, S., Amrein, H., 2010. Ventral lateral and DN1 clock neurons mediate distinct properties of male sex drive rhythm in Drosophila. PNAS 107, 10590-10595.

Gard, A.L., Lenz, P.H., Shaw, J.R., Christie, A.E., 2009. Identification of putative peptide paracrines/hormones in the water flea Daphnia pulex (Crustacea; Branchiopoda; Cladocera) using transcriptomics and immunohistochemistry. Gen. Comp. Endocrinol. 160, 271-287.

George, H., Terracol, R., 1997. The vrille gene of Drosophila is a maternal enhancer of decapentaplegic and encodes a new member of the bZIP family of transcription factors. Genetics 146, 1345-1363.

Glaser, F.T., Stanewsky, R., 2005. Temperature synchronization of the Drosophila circadian clock. Curr. Biol. 15, 1352-1363.

Glaser, F.T., Stanewsky, R., 2007. Synchronization of the Drosophila circadian clock by temperature cycles. Cold Spring Harb. Symp. Quant. Biol. 72, 233-242.

Górska-Andrzejak, J., Salvaterra, P.M., Meinertzhagen, I.A., Krzeptowski, W., Görlich, A., Pyza, E., 2009. Cyclical expression of $\mathrm{Na}^{+} / \mathrm{K}^{+}$-ATPase in the visual system of Drosophila melanogaster. J. Insect Physiol. 55, 459-468.

Granato, F.C., Tironi, T.S., Maciel, F.E., Rosa, C.E., Vargas, M.A., Nery, L.E.M., 2004 Circadian rhythm of pigment migration induced by chromatrophorotropins in melanophores of the crab Chasmagnathus granulata. Comp. Biochem. Physiol. A: Mol. Integr. Physiol. 138, 313-319.

Grima, B., Chélot, E., Xia, R., Rouyer, F., 2004. Morning and evening peaks of activity rely on different clock neurons of the Drosophila brain. Nature 431, 869-873.

Hamanaka, Y., Tanaka, S., Numata, H., Shiga, S., 2007. Peptide immunocytochemistry of neurons projecting to the retrocerebral complex in the blow fly, Protophormia terraenovae. Cell Tissue Res. 329, 581-593.

Hamanaka, Y., Tanaka, S., Numata, H., Shiga, S., 2009. Morphological characterization of neurons projecting to the ring gland in the larval blow fly, Protophormia terraenovae. Zoolog. Sci. 26, 227-237.

Hamanaka, Y., Yasuyama, K., Numata, H., Shiga, S., 2005. Synaptic connections between pigment-dispersing factor-immunoreactive neurons and neurons in the pars lateralis of the blow fly Protophormia terraenovae. J. Comp. Neurol. 491, 390-399.

Hamasaka, Y., Mohrherr, C.J., Predel, R., Wegener, C., 2005. Chronobiological analysis and mass spectrometric characterization of pigment-dispersing factor in the cockroach Leucophaea maderae. J. Insect Sci. 5, 43.

Hardin, P.E., Hall, J.C., Rosbash, M., 1992. Behavioral and molecular analyses suggest that circadian output is disrupted by disconnected mutants in D. melanogaster. EMBO J. 11, 1-6.

Harmar, A.J., Marston, H.M., Shen, S., Spratt, C., West, K.M., Sheward, W.J., Morrison, C.F., Dorin, J.R., Piggins, H.D., Reubi, J.C., Kelly, J.S., Maywood, E.S., Hastings, M.H., 2002. The $\operatorname{VPAC}(2)$ receptor is essential for circadian function in the mouse suprachiasmatic nuclei. Cell 109, 497-508.

Harzsch, S., Dircksen, H., Beltz, B., 2009. Development of pigment-dispersing hormone-immunoreactive neurons in the American lobster: homology to the insect circadian pacemaker system? Cell Tissue Res. 335, 417-429.

Hasegawa, K., Saigusa, T., Tamai, Y., 2005. Caenorhabditis elegans opens up new insights into circadian clock mechanisms. Chronobiol. Int. 22, 1-19.

Hatzold, J., Conradt, B., 2008. Control of apoptosis by asymmetric cell division. PLoS Biol. 6, e84.

Helfrich-Förster, C., 2000. Differential control of morning and evening components in the activity rhythm of Drosophila melanogaster - sex-specific differences suggest a different quality of activity. J. Biol. Rhythms 15, 135-154.

Helfrich-Förster, C., 2004. The circadian clock in the brain: a structural and functional comparison between mammals and insects. J. Comp. Physiol. A: Neuroethol. Sens. Neural Behav. Physiol. 190, 601-613.

Helfrich-Förster, C., 1997. Development of pigment-dispersing hormone-immunoreactive neurons in the nervous system of Drosophila melanogaster. J. Comp. Neurol. 380, 335-354.

Helfrich-Förster, C., 1998. Robust circadian rhythmicity of Drosophila melanogaster requires the presence of lateral neurons: a brain-behavioral study of disconnected mutants. J. Comp. Physiol. A: Sens. Neural Behav. Physiol. 182, 435-453.

Helfrich-Förster, C., Homberg, U., 1993. Pigment-dispersing hormone-immunoreactive neurons in the nervous system of wild-type Drosophila melanogaster and of several mutants with altered circadian rhythmicity. J. Comp. Neurol. 337 $177-190$.

Helfrich-Förster, C., Shafer, O.T., Wülbeck, C., Grieshaber, E., Rieger, D., Taghert, P., 2007. Development and morphology of the clock-gene-expressing lateral neurons of Drosophila melanogaster. J. Comp. Neurol. 500, 47-70.

Helfrich-Förster, C., Tauber, M., Park, J.H., Muhlig-Versen, M., Schneuwly, S., Hofbauer, A., 2000. Ectopic expression of the neuropeptide pigment-dispersing factor alters behavioral rhythms in Drosophila melanogaster. J. Neurosci. 20, 3339-3353.

Hernández-Falcón, J., Moreno-Sáenz, E., Fariás, J.M., Fuentes-Pardo, B., 1987. Role of the sinus gland in crayfish circadian rhythmicity. I. Pseudopupil circadian rhythm. Comp. Biochem. Physiol. A: Physiol. 87, 111-118.

Hines, M.N., 1954. A tidal rhythm in behavior of melanophores in autotomized legs of Uca pugnax. Biol. Bull. 107, 386-396.

Hodge, J.J., Stanewsky, R., 2008. Function of the shaw potassium channel within the Drosophila circadian clock. PLoS One 3, e2274. 
Homberg, U., Davis, N.T., Hildebrand, J.G., 1991a. Peptide-immunocytochemistry of neurosecretory-cells in the brain and retrocerebral complex of the sphinx moth manduca-sexta. J. Comp. Neurol. 303, 35-52.

Homberg, U., Kingan, T.G., Hildebrand, J.G., 1987. Gastrin/CCK-like peptides in the brain ofthe tobacco hawkmoth Manduca sexta. Soc. Neurosci. Abstr. 13, 225.

Homberg, U., Wurden, S., Dircksen, H., Rao, K.R., 1991b. Comparative anatomy of pigment-dispersing hormone-immunoreactive neurons in the brain of orthopteroid insects. Cell Tissue Res. 266, 343-357.

Honda, T., Matsushima, A., Sumida, K., Chuman, Y., Sakaguchi, K., Onoue, H. Meinertzhagen, I.A., Shimohigashi, Y., Shimohigashi, M., 2006. Structural isoforms of the circadian neuropeptide PDF expressed in the optic lobes of the cricket Gryllus bimaculatus: Immunocytochemical evidence from specific monoclonal antibodies. J. Comp. Neurol. 499, 404-421.

Howlader, G., Paranjpe, D.A., Sharma, V.K., 2006. Non-ventral lateral neuron-based, non-PDF-mediated clocks control circadian egg-laying rhythm in Drosophila melanogaster. J. Biol. Rhythms 21, 13-20.

Hsu, Y.W.A., Stemmler, E.A., Messinger, D.I., Dickinson, P.S., Christie, A.E., De la Iglesia, H.O., 2008. Cloning and differential expression of two beta-pigmentdispersing hormone (beta-PDH) isoforms in the crab Cancer productus: evidence for authentic beta-PDH as a local neurotransmitter and beta-PDH II as a humoral factor. J. Comp. Neurol. 508, 197-211.

Hsu, Y.W.A., Stemmler, E.A., Messinger, D.I., Dickinson, P.S., Christie, A.E., De la Iglesia, H.O., 2010. Erratum: cloning and differential expression of two betapigment-dispersing hormone (beta-PDH) isoforms in the crab Cancer productus: evidence for authentic beta-PDH as a local neurotransmitter and beta-PDH II as a humoral factor. J. Comp. Neurol. 518, 4674

Huang, Y., Howlett, E., Stern, M., Jackson, F.R., 2009. Altered LARK expression perturbs development and physiology of the Drosophila PDF clock neurons. Mol. Cell. Neurosci. 41, 196-205.

Husson, S.J., Landuyt, B., Nys, T., Baggerman, G., Boonen, K., Clynen, E., Lindemans, M., Janssen, T., Schoofs, L., 2009. Comparative peptidomics of Caenorhabditis elegans versus C. briggsae by LC-MALDI-TOF MS. Peptides 30, 449-457.

Hyun, S., Lee, Y., Hong, S.T., Bang, S., Paik, D., Kang, J., Shin, J., Lee, J., Jeon, K., Hwang S., Bae, E., Kim, J., 2005. Drosophila GPCR Han is a receptor for the circadian clock neuropeptide PDF. Neuron 48, 267-278.

Im, S.H., Taghert, P.H., 2010. PDF receptor expression reveals direct interactions between circadian oscillators in Drosophila. J. Comp. Neurol. 518, 1925-1945.

Isaac, R.E., Johnson, E.C., Audsley, N., Shirras, A.D., 2007. Metabolic inactivation of the circadian transmitter, pigment dispersing factor (PDF), by neprilysin-like peptidases in Drosophila. J. Exp. Biol. 210, 4465-4470.

Janssen, T., Husson, S.J., Lindemans, M., Mertens, I., Rademakers, S., Ver, D.K., Geysen, J., Jansen, G., Schoofs, L., 2008. Functional characterization of three $\mathrm{G}$ protein-coupled receptors for pigment dispersing factors in Caenorhabditis elegans. J. Biol. Chem. 283, 15241-15249.

Janssen, T., Husson, S.J., Meelkop, E., Temmerman, L., Lindemans, M., Verstraelen, K., Rademakers, S., Mertens, I., Nitabach, M., Jansen, G., Schoofs, L., 2009. Discovery and characterization of a conserved pigment dispersing factor-like neuropeptide pathway in Caenorhabditis elegans. J. Neurochem. 111, 228-241.

Jaramillo, A.M., Zheng, X., Zhou, Y., Amado, D.A., Sheldon, A., Sehgal, A., Levitan, I.B., 2004. Pattern of distribution and cycling of SLOB, Slowpoke channel binding protein, in Drosophila. BMC Neurosci. 5, 3.

Jeon, M., Gardner, H.F., Miller, E.A., Deshler, J., Rougvie, A.E., 1999. Similarity of the $C$ elegans developmental timing protein LIN-42 to circadian rhythm proteins. Science 286, 1141-1146.

Johard, H.A., Yoishii, T., Dircksen, H., Cusumano, P., Rouyer, F., Helfrich-Förster, C., Nässel, D.R., 2009. Peptidergic clock neurons in Drosophila: ion transport peptide and short neuropeptide $\mathrm{F}$ in subsets of dorsal and ventral latera neurons. J. Comp. Neurol. 516, 59-73.

Josefsson, L., 1983. Chemical-properties and physiological actions of crustacean chromatophorotropins. Am. Zool. 23, 507-515.

Kaneko, M., Park, J.H., Cheng, Y., Hardin, P.E., Hall, J.C., 2000. Disruption of synaptic transmission or clock-gene-product oscillations in circadian pacemaker cells of Drosophila cause abnormal behavioral rhythms. J. Neurobiol. 43, 207-233.

Kilman, V.L., Zhang, L., Meissner, R.A., Burg, E., Allada, R., 2009. Perturbing dynamin reveals potent effects on the Drosophila circadian clock. PLoS One 4, e5235.

Kirby, M.S., Nusbaum, M.P., 2007. Central nervous system projections to and from the commissural ganglion of the crab Cancer borealis. Cell Tissue Res. 328, 625-637.

Klarsfeld, A., Malpel, S., Michard-Vanhee, C., Picot, M., Chélot, E., Rouyer, F., 2004 Novel features of cryptochrome-mediated photoreception in the brain circadian clock of Drosophila. J. Neurosci. 24, 1468-1477.

Klein, J.M., De Kleijn, D.P.V., Keller, R., Weidemann, W.M., 1992. Molecular-cloning of crustacean pigment dispersing hormone precursor. Biochem. Biophys. Res. Commun. 189, 1509-1514.

Klein, J.M., Mohrherr, C.J., Sleutels, F., Riehm, J.P., Rao, K.R., 1994. Molecular-cloning of 2 pigment-dispersing hormone ( $\mathrm{PDH}$ ) precursors in the blue crab Callinectes sapidus reveals a novel member of the PDH neuropeptide family. Biochem. Biophys. Res. Commun. 205, 410-416.

Kleinholz, L.H., 1934. Eye stalk hormone and the movement of the distal retinal pigment in palaemonetes. In: Proceedings of the National Academy of Sciences, 20. pp. 659-661.

Kleinholz, L.H., 1936. Crustacean eye-stalk hormone and retinal pigment migration. Biol. Bull. 70, 159-184.

Kleinholz, L.H., 1949. Responses of the proximal retinal pigment of the isolated crustacean eyestalk to light and to darkness. PROC. N.A.S. 35, 215-218.

Kleinholz, L.H., 1975. Purified hormones from crustacean eyestalk and their physiological specificity. Nature 258, 256-257.
Kleinholz, L.H., Rao, K.R., Riehm, J.P., Tarr, G.E., Johnson, L., Norton, S., 1986. Isolation and sequence-analysis of a pigment-dispersing hormone from eyestalks of the crab, Cancer magister. Biol. Bull. 170, 135-143.

Koller, G., 1925. Farbwechsel bei Crangon vulgaris. Verh. Dtsch. Ges. Zool. 30, 128 132.

Koller, G., 1927. Uber chromatophorensystem, Farbensinn und Farbwechsel bei Crangon vulgaris. Z. Vergleich. Physiol. 5, 191-246.

Kula, E., Levitan, E.S., Pyza, E., Rosbash, M., 2006. PDF cycling in the dorsal protocerebrum of the Drosophila brain is not necessary for circadian clock function. J. Biol. Rhythms 21, 104-117.

Kula-Eversole, E., Nagoshi, E., Shang, Y., Rodriguez, J., Allada, R., Rosbash, M., 2010. Surprising gene expression patterns within and between PDF-containing circadian neurons in Drosophila. PNAS 107, 13497-13502.

Lear, B.C., Lin, J.M., Keath, J.R., McGill, J.J., Raman, I.M., Allada, R., 2005a. The ion channel narrow abdomen is critical for neural output of the Drosophila circadian pacemaker. Neuron 48, 965-976.

Lear, B.C., Merrill, C.E., Lin, J.M., Schroeder, A., Zhang, L., Allada, R., 2005b. A G protein-coupled receptor, groom-of-PDF, is required for PDF neuron action in circadian behavior. Neuron 48, 221-227.

Lear, B.C., Zhang, L., Allada, R., 2009. The neuropeptide PDF acts directly on evening pacemaker neurons to regulate multiple features of circadian behavior. PLoS Biol. 7, e1000154.

Lee, C.M., Su, M.T., Lee, H.J., 2009. Pigment dispersing factor: an output regulator of the circadian clock in the German cockroach. J. Biol. Rhythms 24, 35-43.

Li, B., Predel, R., Neupert, S., Hauser, F., Tanaka, Y., Cazzamili, G., Williamsion, M., Arkane, Y., Verleyen, P., Schoofs, L., Schachtner, J., Grimmelikhuijzen, C.J., Park, Y., 2008. Genomics, transcriptomics, and peptidomics of neuropeptides and protein hormones in the red flour beetle Tribolium castaneum. Genome Res. 18, $113-122$.

Lin, Y., Stormo, G.D., Taghert, P.H., 2004. The neuropeptide pigment-dispersing factor coordinates pacemaker interactions in the Drosophila circadian system. J. Neurosci. 24, 7951-7957.

Little, G., 1967. Chromatophore responses in relation to photoperiod and background color in hawaiian ghost crab Ocypode ceratophthalma (Pallas). Pac. Sci. $21,77$.

Lohr, J., Klein, J., Webster, S.G., Dircksen, H., 1993. Quantification, immunoaffinity, purification and sequence-analysis of a pigment-dispersing hormone of the shore crab, Carcinus maenas (L). Comp. Biochem. Physiol. B: Biochem. Mol. Biol. 104, 699-706

Ma, M.M., Bors, E.K., Dickinson, E.S., Kwiatkowski, M.A., Sousa, G.L., Henry, R.P., Smith, C.M., Towle, D.W., Christie, A.E., Li, L.J., 2009a. Characterization of the Carcinus maenas neuropeptidome by mass spectrometry and functional genomics. Gen. Comp. Endocrinol. 161, 320-334.

Ma, M., Wang, J., Chen, R., Li, L., 2009b. Expanding the crustacean neuropeptidome using a multifaceted mass spectrometric approach. J. Proteome Res. 8, 24262437.

Mangerich, S., Keller, R., 1988. Localization of pigment-dispersing hormone (PDH) immunoreactivity in the central nervous system of Carcinus maenas and Orconectes limosus (Crustacea), with reference to FMRFamide immunoreactivity in Orconectes limosus. Cell Tissue Res. 253, 199-208.

Mangerich, S., Keller, R., Dircksen, H., Rao, K.R., Riehm, J.P., 1987. Immunocytochemical localization of pigment-dispersing hormone (PDH) and its coexistence with FMRFamide-immunoreactive material in the eyestalks of the decapod Crustaceans Carcinus maenas and Orconectes limosus. Cell Tissue Res. 250, 365-375.

Matsushima, A., Sato, S., Chuman, Y., Takedo, Y., Yokotani, S., Nose, T., Tominaga, Y. Shimohigashi, M., Shimohigashi, Y., 2004. cDNA cloning of the housefly pigment-dispersing factor (PDF) precursor protein and its peptide comparison among the insect circadian neuropeptides. J. Pept. Sci. 10, 82-91.

Matsushima, A., Takano, K., Yoshida, T., Takeda, Y., Yokotani, S., Shimohigashi, Y., Shimohigashi, M., 2007. Double-labelled in situ hybridization reveals the lack of co-localization of mRNAs for the circadian neuropeptide PDF and FMRFamide in brains of the flies Musca domestica and Drosophila melanogaster. J. Biochem. 141, 867-877.

McCallum, M.L., Rao, K.R., Riehm, J.P., Mohrherr, C.J., Morgan, W.T., 1991. Primary structure and relative potency of an analog of beta-Pdh (pigment-dispersing hormone) from the Crayfish Procambarus clarkii. Pigment Cell Res. 4, 201208.

Meinertzhagen, I.A., Pyza, E., 1996. Daily rhythms in cells of the fly's optic lobe: taking time out from the circadian clock. Trends Neurosci. 19, 285-291.

Meinertzhagen, I.A., Pyza, E., 1999. Neurotransmitter regulation of circadian structural changes in the fly's visual system. Microsc. Res. Tech. 45, 96-105.

Mertens, I. Vandingenen, A., Johnson, E.C., Shafer, O.T., Li, W., Trigg, J.S., De Loof, A. Schoofs, L., Taghert, P.H., 2005. PDF receptor signaling in Drosophila contributes to both circadian and geotactic behaviors. Neuron 48, 213-219.

Meyer-Rochow, V.B., 2001. The crustacean eye: dark/light adaptation, polarization sensitivity, flicker fusion frequency, and photoreceptor damage. Zoolog. Sci. 18 1175-1197.

Miśkiewicz, K., Pyza, E., Schürmann, F.W., 2004. Ultrastructural characteristics of circadian pacemaker neurones, immunoreactive to an antibody against a pigment-dispersing hormone in the fly's brain. Neurosci. Lett. 363, 73-77.

Miśkiewicz, K., Schürmann, F.W., Pyza, E., 2008. Circadian release of pigmentdispersing factor in the visual system of the housefly, Musca domestica. J. Comp. Neurol. 509, 422-435.

Mohrherr, C.J., Maruska, K., Raabe, M., Riehm, J.P., Rao, K.R., 1994. Primary structure of a pigment-dispersing factor from the stick insect, Carausius morosus. Soc. Neurosci. Abstr. 20, 914 
Mohrherr, C.J., Rao, K.R., 1985. Crustacean chromatophorotropic factors from the cricket, Acheta. Am. Zool. 25, A82.

Mohrherr, C.J., Rao, K.R., Riehm, J.P., Morgan, W.T., 1990. Isolation of beta-PDH from sinus glands of the blue-crab, Callinectes sapidus. Am. Zool. 30, A28.

Mohrherr, C.J., Rao, K.R., Riehm, J.P., 1991. Characterization of a pigment-dispersing factor from the American cockroach. Soc. Neurosci. Abstr. 17, 114-116.

Mortin, L.I., Marder, E., 1991. Differential distribution of beta-pigment-dispersing hormone (beta-PDH)-like immunoreactivity in the stomatogastric nervoussystem of 5 species of decapod crustaceans. Cell Tissue Res. 265, 19-33.

Myers, E.M., Yu, J., Sehgal, A., 2003. Circadian control of eclosion: interaction between a central and peripheral clock in Drosophila melanogaster. Curr. Biol. $13,526-533$.

Nässel, D.R., Shiga, S., Mohrherr, C.J., Rao, K.R., 1993. Pigment-dispersing hormonelike peptide in the nervous-system of the flies phormia and Drosophila immunocytochemistry and partial characterization. J. Comp. Neurol. 331, 183-198.

Nässel, D.R., Shiga, S., Wikstrand, E.M., Rao, K.R., 1991. Pigment-dispersing hormone-immunoreactive neurons and their relation to serotonergic neurons in the blowfly and cockroach visual-system. Cell Tissue Res. 266, 511-523.

Nery, L.E., Castrucci, A.M.L., 2002. The Crustacean Nervous System. Springer-Verlag, Berlin.

Newby, L.M., Jackson, F.R., 1993. A new biological rhythm mutant of Drosophila melanogaster that identifies a gene with an essential embryonic function. Genetics 135, 1077-1090.

Nitabach, M.N., Wu, Y., Sheeba, V., Lemon, W.C., Strumbos, J., Zelensky, P.K., White, B.H., Holmes, T.C., 2006. Electrical hyperexcitation of lateral ventral pacemaker neurons desynchronizes downstream circadian oscillators in the fly circadian circuit and induces multiple behavioral periods. J. Neurosci. 26, 479-489.

Ohira, T., Nagasawa, H., Aida, K., 2002. Molecular cloning of cDNAs encoding two pigment-dispersing hormones and two corresponding genes from the kuruma prawn (Penaeus japonicus). Mar. Biotechnol. 4, 463-470.

Ohira, T., Tsutsui, N., Kawazoe, I., Wilder, M.N., 2006. Isolation and characterization of two pigment-dispersing hormones from the whiteleg shrimp, Litopenaeus vannamei. Zoolog. Sci. 23, 601-606.

Okamoto, A., Mori, H., Tomioka, K., 2001. The role of the optic lobe in circadian locomotor rhythm generation in the cricket, Gryllus bimaculatus, with special reference to PDH-immunoreactive neurons. J. Insect Physiol. 47, 889-895.

Olivo, R.F., Larsen, M.E., 1978. Brief exposure to light initiates screening pigment migration in retinula cells of crayfish, Procambarus. J. Comp. Physiol. 125, 9196.

Park, D., Griffith, L.C., 2006. Electrophysiological and anatomical characterization of PDF-positive clock neurons in the intact adult Drosophila brain. J. Neurophysiol. 95, 3955-3960.

Park, J.H., Hall, J.C., 1998. Isolation and chronobiological analysis of a neuropeptide pigment-dispersing factor gene in Drosophila melanogaster. J. Biol. Rhythms 13, 219-228.

Park, J.H., Helfrich-Förster, C., Lee, G., Liu, L., Rosbash, M., Hall, J.C., 2000. Differential regulation of circadian pacemaker output by separate clock genes in Drosophila. In: Proceedings of the National Academy of Sciences of the United States of America, vol. 97. pp. 3608-3613.

Parkinson, J., Mitreva, M., Whitton, C., Thomson, M., Daub, J., Martin, J., Schmid, R., Hall, N., Barrell, B., Waterston, R.H., McCarter, J.P., Blaxter, M.L., 2004. A transcriptomic analysis of the phylum Nematoda. Nat. Genet. 36, 1259-1267.

Peng, Y., Stoleru, D., Levine, J.D., Hall, J.C., Rosbash, M., 2003. Drosophila free-running rhythms require intercellular communication. PLoS Biol. 1, E13.

Perkins, E.B., 1928. Color changes in crustaceans, especially in Palaemonetes. J. Exp. Zool. 50, 71-105.

Persson, M.G.S., Eklund, M.B., Dircksen, H., Muren, J.E., Nässel, D.R., 2001. Pigmentdispersing factor in the locust abdominal ganglia may have roles as circulating neurohormone and central neuromodulator. J. Neurobiol. 48, 19-41.

Petri, B., Stengl, M., 1997. Pigment-dispersing hormone shifts the phase of the circadian pacemaker of the cockroach Leucophaea maderae. J. Neurosci. 17, 4087-4093.

Phillips, J.M., Fox, D.L., Bonomelli, S., Rao, K.R., Riehm, J.P., 1990. Immunocytochemical studies of the distribution of alpha-PDH and beta-PDH in Callinectes and Pandalus. Am. Zool. 30, A28.

Picot, M., Cusumano, P., Klarsfeld, A., Ueda, R., Rouyer, F., 2007. Light activates output from evening neurons and inhibits output from morning neurons in the Drosophila circadian clock. PLoS Biol. 5, e315.

Picot, M., Klarsfeld, A., Chélot, E., Malpel, S., Rouyer, F., 2009. A role for blind DN2 clock neurons in temperature entrainment of the Drosophila larval brain. J. Neurosci. 29, 8312-8320.

Porras, M.G., De Loof, A., Breuer, M., Aréchiga, H., 2003. Corazonin promotes tegumentary pigment migration in the crayfish Procambarus clarkii. Peptides 24, 1581-1589.

Prosser, C.L., 1934. Action potentials in the nervous system of the crayfish. II. Responses to illumination of the eye and the caudal ganglion. J.Cell Comp. Physiol. 4, 363-377.

Pyza, E., Meinertzhagen, I.A., 1997. Circadian rhythms in screening pigment and invaginating organelles in photoreceptor terminals of the housefly's first optic neuropile. J. Neurobiol. 32, 517-529.

Pyza, E., Meinertzhagen, I.A., 2003. The regulation of circadian rhythms in the fly's visual system: involvement of FMRFamide-like neuropeptides and their relationship to pigment dispersing factor in Musca domestica and Drosophila melanogaster. Neuropeptides 37, 277-289.
Pyza, E., Meinertzhagen, I.A., 1996. Neurotransmitters regulate rhythmic size changes amongst cells in the fly's optic lobe. J. Comp. Physiol. A: Sens. Neural Behav. Physiol. 178, 33-45.

Rao, K.R., 2001. Crustacean pigmentary-effector hormones: chemistry and functions of RPCH, PDH, and related peptides. Am. Zool. 41, 364-379.

Rao, K.R., Mohrherr, C.J., Riehm, J.P., Zahnow, C.A., Norton, S., Johnson, L., Tarr, G.E., 1987. Primary structure of an analog of crustacean pigment-dispersing hormone from the lubber grasshopper Romalea microptera. J. Biol. Chem. 262, 2672-2675.

Rao, K.R., Riehm, J.P., 1993. Pigment-dispersing hormones. Ann. N. Y. Acad. Sci. 680, 78-88.

Rao, K.R., Riehm, J.P., 1989. The pigment-dispersing hormone family - chemistry, structure-activity relations, and distribution. Biol. Bull. 177, 225-229.

Rao, K.R., Riehm, J.P., Zahnow, C.A., Kleinholz, L.H., Tarr, G.E., Johnson, L., Norton, S. Landau, M., Semmes, O.J., Sattelberg, R.M., Jorenby, W.H., Hintz, M.F., 1985 Characterization of A pigment-dispersing hormone in eyestalks of the fiddler crab Uca pugilator. In: Proceedings of the National Academy of Sciences of the United States of America, 82. pp. 5319-5322.

Reischig, T., Petri, B., Stengl, M., 2004. Pigment-dispersing hormone (PDH)-immunoreactive neurons form a direct coupling pathway between the bilaterally symmetric circadian pacemakers of the cockroach Leucophaea maderae. Cell Tissue Res. 318, 553-564.

Reischig, T., Stengl, M., 2003a. Ectopic transplantation of the accessory medulla restores circadian locomotor rhythms in arrhythmic cockroaches (Leucophaea maderae). J. Exp. Biol. 206, 1877-1886.

Reischig, T., Stengl, M., 2003b. Ultrastructure of pigment-dispersing hormoneimmunoreactive neurons in a three-dimensional model of the accessory medulla of the cockroach Leucophaea maderae. Cell Tissue Res. 314, 421435.

Renn, S.C., Park, J.H., Rosbash, M., Hall, J.C., Taghert, P.H., 1999. A pdf neuropeptide gene mutation and ablation of PDF neurons each cause severe abnormalities of behavioral circadian rhythms in Drosophila. Cell 99, 791-802.

Rieger, D., Shafer, O.T., Tomioka, K., Helfrich-Förster, C., 2006. Functional analysis of circadian pacemaker neurons in Drosophila melanogaster. J. Neurosci. 26, 25312543.

Roller, L., Yamanaka, N., Watanabe, K., Daubnerová, I., Zitnan, D., Kataoka, H. Tanaka, Y., 2008. The unique evolution of neuropeptide genes in the silkworm Bombyx mori. Insect Biochem. Mol. Biol. 38, 1147-1157.

Saifullah, A.S.M., Tomioka, K., 2003. Pigment-dispersing factor sets the night state of the medulla bilateral neurons in the optic lobe of the cricket, Gryllus bimaculatus. J. Insect Physiol. 49, 231-239.

Saigusa, T., Ishizaki, S., Watabiki, S., Ishii, N., Tanakadate, A., Tamai, Y., Hasegawa, K., 2002. Circadian behavioural rhythm in Caenorhabditis elegans. Curr. Biol. 12, R46-R47.

Sandeman, D., Sandeman, R., Derby, C., Schmidt, M., 1992. Morphology of the brain of crayfish, crabs, and spiny lobsters: a common nomenclature for homologous structures. Biol. Bull. 183, 304-326.

Sandeman, D.C., Sandeman, R.E., de Couet, H.G., 1990. Extraretinal photoreceptors in the brain of the crayfish Cherax destructor. J. Neurobiol. 21, 619-629.

Sato, S., Chuman, Y., Matsushima, A., Tominaga, Y., Shimohigashi, Y., Shimohigashi, M., 2002. A circadian neuropeptide, pigment-dispersing factor-PDF, in the lastsummer cicada Meimuna opalifera: cDNA cloning and immunocytochemistry. Zoolog. Sci. 19, 821-828.

Schneider, N.L., Stengl, M., 2005. Pigment-dispersing factor and GABA synchronize cells of the isolated circadian clock of the cockroach Leucophaea maderae. J. Neurosci. 25, 5138-5147.

Schueler, P.A., Elde, R.P., Herman, W.S., Mahoney, W.C., 1986. Identification and initial characterization of adipokinetic hormone-like immunoreactive peptides of rat origin. J. Neurochem. 47, 133-138.

Sehadová, H., Glaser, F.T., Gentile, C., Simoni, A., Giesecke, A., Albert, J.T., Stanewsky, R., 2009. Temperature entrainment of Drosophila's circadian clock involves the gene nocte and signaling from peripheral sensory tissues to the brain. Neuron 64, 251-266.

Sehadová, H., Sauman, I., Sehnal, F., 2003. Immunocytochemical distribution of pigment-dispersing hormone in the cephalic ganglia of polyneopteran insects. Cell Tissue Res. 312, 113-125.

Settembrini, B.P., Villar, M.J., 2005. FMRFamide-like immunocytochemistry in the brain and subesophageal ganglion of Triatoma infestans (Insecta: Heteroptera). Coexpression with beta-pigment-dispersing hormone and small cardioactive peptide B. Cell Tissue Res. 321, 299-310.

Shafer, O.T., Kim, D.J., Dunbar-Yaffe, R., Nikolaev, V.O., Lohse, M.J., Taghert, P.H., 2008. Widespread receptivity to neuropeptide PDF throughout the neuronal circadian clock network of Drosophila revealed by real-time cyclic AMP imaging. Neuron 58, 223-237.

Sheeba, V., Fogle, K.J., Kaneko, M., Rashid, S., Chou, Y.T., Sharma, V.K., Holmes, T.C. 2008a. Large ventral lateral neurons modulate arousal and sleep in Drosophila. Curr. Biol. 18, 1537-1545.

Sheeba, V., Gu, H., Sharma, V.K., O’Dowd, D.K., Holmes, T.C., 2008b. Circadian- and light-dependent regulation of resting membrane potential and spontaneous action potential firing of Drosophila circadian pacemaker neurons. J. Neurophysiol. 99, 976-988.

Sheeba, V., Sharma, V.K., Gu, H., Chou, Y.T., O'Dowd, D.K., Holmes, T.C., 2008c Pigment dispersing factor-dependent and -independent circadian locomotor behavioral rhythms. J. Neurosci. 28, 217-227.

Silbiger, N., Munguia, P., 2008. Carapace color change in Uca pugilator as a response to temperature. J. Exp. Mar. Biol. Ecol. 355, 41-46. 
Silvegren, G., Lofstedt, C., Qi, R.W., 2005. Circadian mating activity and effect of pheromone pre-exposure on pheromone response rhythms in the moth Spodoptera littoralis. J. Insect Physiol. 51, 277-286.

Simonetta, S.H., Golombek, D.A., 2007. An automated tracking system for Caenorhabditis elegans locomotor behavior and circadian studies application. J. Neurosci. Methods 161, 273-280.

Simonetta, S.H., Migliori, M.L., Romanowski, A., Golombek, D.A., 2009. Timing of locomotor activity circadian rhythms in Caenorhabditis elegans. PLoS One 4 e7571.

Simonetta, S.H., Romanowski, A., Minniti, A.N., Inestrosa, N.C., Golombek, D.A., 2008. Circadian stress tolerance in adult Caenorhabditis elegans. J. Comp. Physiol. A: Neuroethol. Sens. Neural Behav. Physiol. 194, 821-828.

Singaravel, M., Fujisawa, Y., Hisada, M., Saifullah, A.S., Tomioka, K., 2003. Phase shifts of the circadian locomotor rhythm induced by pigment-dispersing factor in the cricket Gryllus bimaculatus. Zoolog. Sci. 20, 1347-1354.

Somers, D.E., Devlin, P.F. Kay, S.A., 1998. Phytochromes and cryptochromes in the entrainment of the Arabidopsis circadian clock. Science 282, 1488-1490.

Sousa, G.L., Lenz, P.H., Hartline, D.K., Christie, A.E., 2008. Distribution of pigment dispersing hormone- and tachykinin-related peptides in the central nervous system of the copepod crustacean Calanus finmarchicus. Gen. Comp. Endocrinol $156,454-459$

Stanewsky, R., Kaneko, M., Emery, P., Beretta, B., Wager-Smith, K., Kay, S.A., Rosbash M., Hall, J.C., 1998. The cryb mutation identifies cryptochrome as a circadian photoreceptor in Drosophila. Cell 95, 681-692.

Stengl, M., Homberg, U., 1994. Pigment-dispersing hormone-immunoreactive neurons in the cockroach Leucophaea maderae share properties with circadian pacemaker neurons. J. Comp. Physiol. A: Sens. Neural Behav. Physiol. 175, 203-213.

Stoleru, D., Peng, Y., Agosto, J., Rosbash, M., 2004. Coupled oscillators control morning and evening locomotor behaviour of Drosophila. Nature 431, 862868.

Stoleru, D., Peng, Y., Nawathean, P., Rosbash, M., 2005. A resetting signal between Drosophila pacemakers synchronizes morning and evening activity. Nature 438 , 238-242.

Strauss, J., Dircksen, H., 2010. Circadian clocks in crustaceans: identified neuronal and cellular systems. Front. Biosci. 15, 1040-1074.

Stuart, A.E., Borycz, J., Meinertzhagen, I.A., 2007. The dynamics of signaling at the histaminergic photoreceptor synapse of arthropods. Prog. Neurobiol. 82, 202227

Stuart, A.E., Callaway, J.C., 1991. Histamine: the case for a photoreceptor's neurotransmitter. Neurosci. Res. Suppl. 15, S13-S23.

Sullivan, J.M., Genco, M.C., Marlow, E.D., Benton, J.L., Beltz, B.S., Sandeman, D.C. 2009. Brain photoreceptor pathways contributing to circadian rhythmicity in crayfish. Chronobiol. Int. 26, 1136-1168.

Taghert, P.H., 2009. Circadian biology: a neuropeptide is bound to activate its receptor. Curr. Biol. 19, R696-R697.

Taghert, P.H., Hewes, R.S., Park, J.H., O’Brien, M.A., Han, M., Peck, M.E., 2001. Multiple amidated neuropeptides are required for normal circadian locomotor rhythms in Drosophila. J. Neurosci. 21, 6673-6686.

Taghert, P.H., Shafer, O.T., 2006. Mechanisms of clock output in the Drosophila circadian pacemaker system. J. Biol. Rhythms 21, 445-457.

Takeda, S., 2006. Behavioural evidence for body colour signaling in the fiddler crab Uca perplexa (Brachyura: Ocypodidae). J. Exp. Mar. Biol. Ecol. 330, 521-527.

Tanoue, S., Krishnan, P., Krishnan, B., Dryer, S.E., Hardin, P.E., 2004. Circadian clocks in antennal neurons are necessary and sufficient for olfaction rhythms in Drosophila. Curr. Biol. 14, 638-649.

Thresher, R.J., Vitaterna, M.H., Miyamoto, Y., Kazantsev, A., Hsu, D.S., Petit, C., Selby, C.P., Dawut, L., Smithies, O., Takahashi, J.S., Sancar, A., 1998. Role of mouse cryptochrome blue-light photoreceptor in circadian photoresponses. Science 282, 1490-1494.

Thurman, C.L., 1988. Rhythmic physiological color-change in crustacea - a review. Comp. Biochem. Physiol. C: Pharmacol. Toxicol. Endocrinol. 91, 171-185.

Toma, D.P., White, K.P., Hirsch, J., Greenspan, R.J., 2002. Identification of genes involved in Drosophila melanogaster geotaxis, a complex behavioral trait. Nat. Genet. 31, 349-353.

Tomioka, K., Abdelsalam, S., 2004. Circadian organization in hemimetabolous insects. Zoolog. Sci. 21, 1153-1162.

Tsai, L.T., Bainton, R.J., Blau, J., Heberlein, U., 2004. Lmo mutants reveal a novel role for circadian pacemaker neurons in cocaine-induced behaviors. PLoS Biol. 2 , e408

Vafopoulou, X., Steel, C.G.H., Terry, K.L., 2007. Neuroanatomical relations of prothoracicotropic hormone neurons with the circadian timekeeping system in the brain of larval and adult Rhodnius prolixus (Hemiptera). J. Comp. Neurol. 503, 511-524.

Vafopoulou, X., Terry, K.L., Steel, C.G., 2010. The circadian timing system in the brain of the fifth larval instar of Rhodnius prolixus (hemiptera). J. Comp. Neurol. 518 1264-1282.

Veenstra, J.A., Agricola, H.J., Sellami, A., 2008. Regulatory peptides in fruit fly midgut Cell Tissue Res. 334, 499-516.

Verde, M.A., Barriga-Montoya, C., Fuentes-Pardo, B., 2007. Pigment dispersing hormone generates a circadian response to light in the crayfish, Procambarus clarkii. Comp. Biochem. Physiol. A: Mol. Integr. Physiol. 147, 983-992.
Vosko, A.M., Schroeder, A., Loh, D.H., Colwell, C.S., 2007. Vasoactive intestinal peptide and the mammalian circadian system. Gen. Comp. Endocrinol. 152, $165-175$.

Wang, X.D., Jia, H.T., Chamberlin, H.M., 2006. The bZip proteins CES-2 and ATF-2 alter the timing of transcription for a cell-specific target gene in C. elegans. Dev. Biol. 289, 456-465.

Weiss, R., Dov, A., Fahrbach, S.E., Bloch, G., 2009. Body size-related variation in pigment dispersing factor-immunoreactivity in the brain of the bumblebee Bombus terrestris (Hymenoptera, Apidae). J. Insect Physiol. 55, 479-487.

Welsh, J.H., 1930. The mechanisms of the migration of the distal pigment cells in the eyes of Palaemonetes. J. Exp. Zool. 56, 459-494.

Welsh, J.H., 1939. The action of eye-stalk extracts on retinal pigment migration in the crayfish, Cambarus bartoni. Biol. Bull. 77, 119-125.

Wen, C.J., Lee, H.J., 2008. Mapping the cellular network of the circadian clock in two cockroach species. Arch. Insect Biochem. Physiol. 68, 215-231.

Wilkens, L.A., Larimer, J.L., 1972. The CNS photoreceptor of crayfish: morphology and synaptic activity. J. Cell Comp. Physiol. 80, 389-407.

Williams, J.A., Su, H.S., Bernards, A., Field, J., Sehgal, A., 2001. A circadian output in Drosophila mediated by neurofibromatosis-1 and Ras/MAPK. Science 293, 2251-2256.

Wise, S., Davis, N.T., Tyndale, E., Noveral, J., Folwell, M.G., Bedian, V., Emery, I.F., Siwicki, K.K., 2002. Neuroanatomical studies of period gene expression in the hawkmoth, Manduca sexta. J. Comp. Neurol. 447, 366-380.

Wu, Y., Cao, G., Nitabach, M.N., 2008a. Electrical silencing of PDF neurons advances the phase of non-PDF clock neurons in Drosophila. J. Biol. Rhythms 23, 117-128.

Wu, Y., Cao, G., Pavlicek, B., Luo, X., Nitabach, M.N., 2008b. Phase coupling of a circadian neuropeptide with rest/activity rhythms detected using a membranetethered spider toxin. PLoS Biol. 6, e273.

Wülbeck, C., Grieshaber, E., Helfrich-Förster, C., 2008. Pigment-dispersing factor (PDF) has different effects on Drosophila's circadian clocks in the accessory medulla and in the dorsal brain. J. Biol. Rhythms 23, 409-424.

Wülbeck, C., Grieshaber, E., Helfrich-Förster, C., 2009. Blocking endocytosis in Drosophila's circadian pacemaker neurons interferes with the endogenous clock in a PDF-dependent way. Chronobiol. Int. 26, 1307-1322.

Yamano, K., Unuma, T., 2006. Expressed sequence tags from eyestalk of kuruma prawn, Marsupenaeus japonicus. Comp. Biochem. Physiol. A: Mol. Integr. Physiol. 143, 155-161.

Yang, W.J., Aida, K., Nagasawa, H., 1999. Characterization of chromatophorotropic neuropeptides from the kuruma prawn Penaeus japonicus. Gen. Comp. Endocrinol. 114, 415-424.

Yang, Y.Y., Wen, C.J., Mishra, A., Tsai, C.W., Lee, H.J., 2009. Development of the circadian clock in the German cockroach, Blattella germanica. J. Insect Physiol. $55,469-478$.

Yasuyama, K., Okada, Y., Hamanaka, Y., Shiga, S., 2006. Synaptic connections between eyelet photoreceptors and pigment dispersing factor-immunoreactive neurons of the blowfly Protophormia terraenovae. J. Comp. Neurol. 494, $331-$ 344

Yoshii, T., Heshiki, Y., Ibuki-Ishibashi, T., Matsumoto, A., Tanimura, T., Tomioka, K., 2005. Temperature cycles drive Drosophila circadian oscillation in constant light that otherwise induces behavioural arrhythmicity. Eur. J. Neurosci. 22, 11761184

Yoshii, T., Wülbeck, C., Sehadová, H., Veleri, S., Bichler, D., Stanewsky, R., HelfrichFörster, C., 2009. The neuropeptide pigment-dispersing factor adjusts period and phase of Drosophila's clock. J. Neurosci. 29, 2597-2610.

Zahnow, C.A., Rao, K.R., Mohrherr, C.J., Riehm, J.P., 1987. Immunocytochemistry of neuropeptides in the cephalic neuroendocrine system of the lubber grasshopper, Romalea microptera. Soc. Neurosci. Abstr. 13, 993.

Závodská, R., Sauman, I., Sehnal, F., 2003. Distribution of PER protein, pigmentdispersing hormone, prothoracicotropic hormone, and eclosion hormone in the cephalic nervous system of insects. J. Biol. Rhythms 18, 106-122.

Závodská, R., Wen, C.J., Hrdy, I., Sauman, I., Lee, H.J., Sehnal, F., 2008. Distribution of corazonin and pigment-dispersing factor in the cephalic ganglia of termites. Arthropod. Struct. Dev. 37, 273-286.

Závodská, R., Wen, C.J., Sehnal, F., Hrdy, I., Lee, H.J., Sauman, I., 2009. Corazonin- and PDF-immunoreactivities in the cephalic ganglia of termites. J. Insect Physiol. 55, 441-449.

Zhang, L., Chung, B.Y., Lear, B.C., Kilman, V.L., Liu, Y., Mahesh, G., Meissner, R.A., Hardin, P.E., Allada, R., 2010a. DN1(p) circadian neurons coordinate acute light and PDF inputs to produce robust daily behavior in Drosophila. Curr. Biol. 20, 591-599.

Zhang, L., Lear, B.C., Seluzicki, A., Allada, R., 2009. The CRYPTOCHROME photoreceptor gates PDF neuropeptide signaling to Set circadian network hierarchy in Drosophila. Curr. Biol. 19, 2050-2055.

Zhang, Y., Liu, Y., Bilodeau-Wentworth, D., Hardin, P.E., Emery, P., 2010b. Light and temperature control the contribution of specific DN1 neurons to Drosophila circadian behavior. Curr. Biol. 20, 600-605.

Zheng, X., Koh, K., Sowcik, M., Smith, C.J., Chen, D., Wu, M.N., Sehgal, A., 2009. An isoform-specific mutant reveals a role of PDP1 epsilon in the circadian oscillator. J. Neurosci. 29, 10920-10927.

Zhou, X., Yuan, C., Guo, A., 2005. Drosophila olfactory response rhythms require clock genes but not pigment dispersing factor or lateral neurons. J. Biol. Rhythms 20, 237-244. 